\title{
HUESO, ASTA Y MARFIL: MANUFACTURA DE ARTEFACTOS DURANTE EL III MILENIO A.C. EN EL POBLADO DE Los CAstillejos (MonTEFrío, GRAnADA)
}

\begin{abstract}
En el presente trabajo se exponen los resultados del estudio de los artefactos manufacturados en hueso, asta y marfil procedentes de los depósitos del III milenio a.C. del poblado de Los Castillejos, hasta ahora prácticamente inéditos. Se ha llevado a cabo su análisis formal y la determinación de la materia prima, observándose un predominio claro del hueso para la mayor parte de los artefactos, y seleccionando el asta de ciervo y el marfil para elementos de carácter especial. La minuciosa observación microscópica de la superficie de los artefactos ha revelado los procesos de manufactura, siendo la fracturación y la bipartición los métodos principales para obtener los soportes. Se ha obtenido, además, un gran volumen de información social, económica y cultural, detectándose incluso tradiciones en la manufactura que arrancan en la segunda mitad del IV milenio a.C.
\end{abstract}

Palabras clave: tecnología ósea, materias primas duras animales, Edad del Cobre, Los Castillejos de Montefrío.

BONE, ANTLER, AND IVORY: THE MANUfACTURE OF OSSEOUS ARTIFACTS DURING THE III MILLENNIUM BC AT THE LOS Castillejos site (Montefrío, Granada)

Hard animal materials had a very significant role in prehistoric societies. This paper focuses on the study of the worked osseous assemblage documented at the III millenium BC layers from the Los Castillejos site, which has remained unpublished until now. The raw material identification has revealed a major use of bone as raw material to manufacture tools. However, both red deer antler and elephant ivory were carefully selected to manufacture especial objects. The microscopic analyses of the surface of the artefatcs, have been undertaken in order to know how these objects were manufactured. Both fracture and splitting were the main methods to get the blanks. Moreover, a great amount of information related to social, economic and cultural aspects, has come to light. Some cultural and technical traditions have been observed.

Key words: osseous technology, hard animal materials, Copper Age, Los Castillejos de Montefrio.

El poblado de Los Castillejos se encuentra situado en el extremo occidental de Las Peñas de los Gitanos, en Montefrío (Granada). Se encuadra en la región geográfica de Los Montes, que formando parte de las Sierras Subbéticas, se extiende a lo largo del límite septentrional de la provincia granadina entre la Sierra de Loja al O y el pasillo de Pozo Alcón al E, constituyendo el borde septentrional de la Depresión de Granada (fig. 1).
Si bien el yacimiento de las Peñas de los Gitanos (poblado y necrópolis megalítica) es conocido desde antiguo (Góngora 1868; Gómez 1907; 1949; Leisner y Leisner 1943; Mergelina 1941-42; 1945-46), las primeras intervenciones arqueológicas no tuvieron lugar hasta mediados del s. XX (Tarradell 1947, 1952). Tarradell abrió dos grandes zanjas en el poblado y excavó varias cuevas, entre ellas la de Cueva Alta. Como resultado, se documentó una amplia 


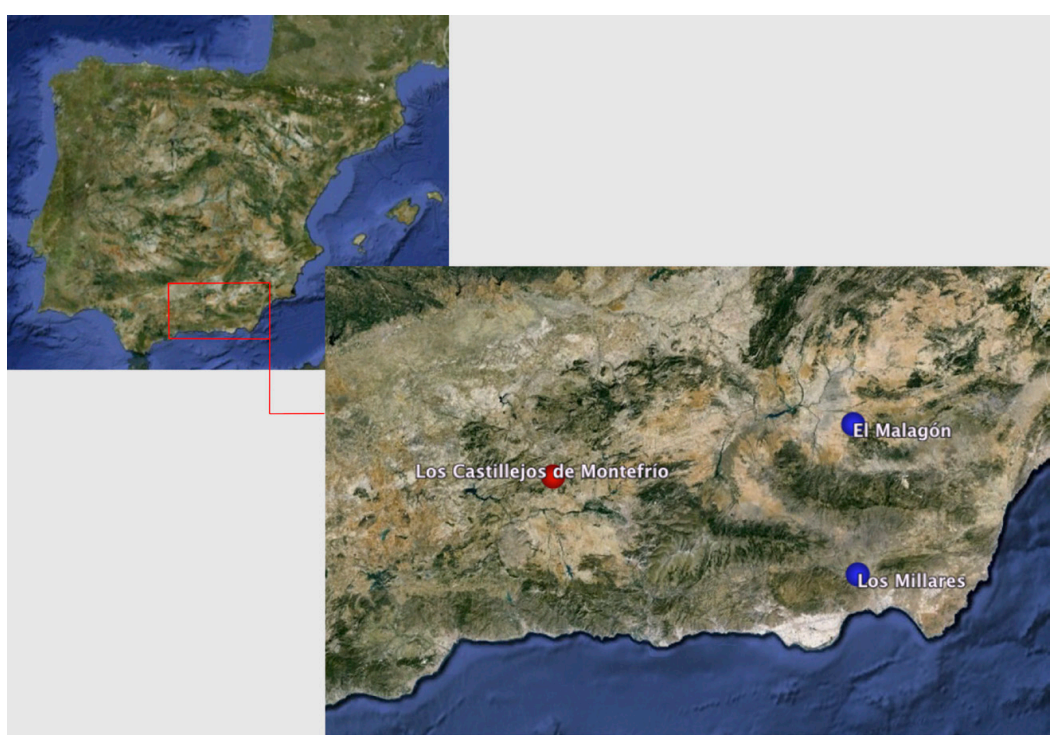

Fig. 1. Situación de Los Castillejos en Las Peñas de los Gitanos, Montefrío (Granada).

secuencia de ocupación prehistórica que arrancaba en el Neolítico, advirtiéndose diferentes ocupaciones posteriores en el tiempo, de época ibérica, romana, visigoda y árabe.

Será a partir del año 1968 cuando el Departamento de Prehistoria y Arqueología de la Universidad de Granada, preocupado tanto por la conservación como por la valoración del conjunto arqueológico, se interese por las posibilidades de excavación del yacimiento, de cara a obtener un mejor conocimiento de la secuencia estratigráfica y documentar las estructuras de hábitat y necrópolis.

Así, en 1971 se llevó a cabo la primera campaña de excavación, en la que se abrieron cuatro cortes, profundizándose tan solo en uno de ellos, el Corte 1, hasta la roca. Uno de los objetivos de esta campaña fue también realizar un sondeo estratigráfico en una de las cuevas próximas, eligiendo la Cueva de las Tontas al no mostrar evidencias de expolio ni excavaciones previas (Del Pino 1984). La secuencia documentada en él, quedó confirmada y ampliada tras la ampliación de ocho cortes más en la intervención de 1974 (Arribas y Molina 1977; 1978; 1979).

Trabajos más recientes en el tiempo desarrollados también por la Universidad de Granada en los años noventa y en la primera década del s. XXI, vinieron a completar el conocimiento de la secuencia estratigráfica que se había establecido gracias a las intervenciones anteriores, viéndose ligeramente modificada (Afonso et al. 1996; Ramos et al. 1997; Cámara et al. 2005; 2010). De ella, nos interesan fundamentalmente los momentos de ocupación prehistórica.
Nuestro estudio se centra en el análisis de los objetos óseos procedentes de la ocupación del poblado durante la Edad del Cobre, que de acuerdo con las fechas radiocarbónicas (AMS) comprende entre un 3300 cal a.C. y un 2000 cal a.C. (Cámara et al. 2010). Según la secuencia estratigráfica del asentamiento, este marco cronológico abarca los denominados Períodos V, VI, VII y VIII:

- Período V (3300-3000 cal a.C.): corresponde a un Cobre Antiguo y abarca las Fases $16 \mathrm{~b}$ y 17. El registro arqueológico muestra fuentes cerámicas de borde engrosado y perfil continuo, estando habitualmente bruñidas o alisadas por ambas caras, así como placas de arcilla con una o dos perforaciones tal vez usadas como pesas de telar. En los momentos finales de este período se observa la presencia de los primeros elementos metálicos.

- Período VI (3000-2600 cal a.C.): corresponde a un Cobre Pleno, con las Fases 18 y 19. Se documentan cabañas de tendencia circular, con zócalo de piedra y alzado de cañas revestidas con barro. En el interior de éstas abundan las concentraciones de cuernecillos de arcilla asociadas a pesas ovales con cuatro perforaciones y elementos apuntados de hueso, lo que puede relacionarse con actividades textiles. En los momentos finales del período se documentan los primeros botones de perforación en $\mathrm{V}$ de marfil.

- Período VII (2600-2400 cal a.C.): corresponde a un Cobre Tardío y engloba las Fases 20, 21 y 22. Las estructuras de habitación guardan características estructurales e internas similares, habiéndose documentado una zona de talla de puntas de flecha de base cóncava, 
un área de telar con pesas ovales y otra zona de molienda. Se observa un incremento de las fuentes y platos cerámicos de borde biselado.

- Período VIII (2400-2000 cal a.C.): corresponde a un Cobre Final, con las Fases 23a, 23b y 23c. La cultura material mueble viene caracterizada por la presencia de grandes orzas de almacenamiento y campaniformes incisos. Se documenta la construcción del primer muro de cierre del poblado.

\section{EL CONJUNTO DE INDUSTRIA ÓSEA DE LOS CASTILLEJOS}

En el transcurso de las intervenciones arqueológicas llevadas a cabo entre 1946 y 1947 (Tarradell 1947) y 1971 y 1974 (Arribas 1976; Arribas y Molina 1977; 1978; 1979), se documentó un amplio conjunto de artefactos óseos en el asentamiento. De ellos, un total de 121 pertenecen a contextos del III milenio a.C., así como a la fase de transición entre éste y el IV milenio a.C.

Todos estos útiles y objetos de adorno de hueso formaron parte de la muestra que Vicente Salvatierra estudiara en su trabajo para obtener el título de doctor, aún inédito (Salvatierra 1982). Además, las piezas realizadas en materias óseas documentadas en las excavaciones de Tarradell fueron publicadas en un pequeño artículo sobre los materiales hallados entre 1946 y 1947, si bien fueron analizadas de manera muy superficial (Moreno 1982). Dado el avance de la investigación en las últimas décadas, hemos considerado conveniente volver a revisar este material empleando nuevos enfoques, perspectivas y metodologías (Altamirano 2013a; 2014a, b).

En nuestro trabajo, hemos observado que de los 121 artefactos óseos que hemos seleccionado para estudio, 101 son útiles y tan sólo 10 han sido clasificados como piezas de adorno personal o de carácter simbólico/religioso.

\section{LA MATERIA PRIMA}

En lo que respecta a la materia prima, el hueso es el material predominante para la manufactura de artefactos de morfología diversa, con un $85 \%$ de la muestra (fig. 2). Le sigue de lejos el asta de ciervo, con una explotación de la misma no demasiado significativa (8\%), aunque dedicada a la elaboración de algunos útiles especializados, como el hacha-martillo que ha sido analizada recientemente (Altamirano 2013a, b).
La presencia de marfil sí es destacable, con hasta ocho artefactos de características muy concretas, todos ellos relacionados con elementos de adorno personal (7\%). Gracias al análisis macro y microscópico de las piezas, hemos determinado su obtención a partir de colmillos de elefante. Desconocemos por el momento si se trata de marfil procedente de elefante africano, bien de estepa (Loxodonta africana africana), bien de bosque (Loxodonta africana cyclotis), o si por el contrario procede de elefante asiático (Elephas maximus). Según diversos análisis de piezas ebúrneas del III milenio a.C. procedentes del $\mathrm{S}$ peninsular, parece observarse una presencia mayoritaria de marfil asiático, existiendo también evidencias de trabajo de marfil fósil de Elephas (Palaeoloxodon antiquus) (Banerjee y Huth 2012; Schuhmacher 2012;

\begin{tabular}{|c|c|c|c|}
\hline ESPECIE & ANATOMÍA & $\mathbf{N}^{0}$ & $\%$ \\
\hline $\begin{array}{l}\text { Bóvido } \\
\text { (Bos taurus/Bos domesticus) }\end{array}$ & Costilla & 9 & $6 \%$ \\
\hline \multirow{3}{*}{$\begin{array}{l}\text { Ciervo rojo } \\
\text { (Cervus elaphus) }\end{array}$} & Asta & 8 & \multirow[b]{3}{*}{$8 \%$} \\
\hline & Incisivo & 1 & \\
\hline & Falange & 2 & \\
\hline \multirow[t]{4}{*}{ Bóvido/Ciervo } & Costilla & 3 & \multirow[b]{4}{*}{$18 \%$} \\
\hline & Metápodo & 5 & \\
\hline & Tibia & 2 & \\
\hline & Tibia/Metápodo & 17 & \\
\hline Équido (Equss sp.) & Metápodo lateral & 1 & $1 \%$ \\
\hline \multirow{4}{*}{$\begin{array}{l}\text { Ovicáprido } \\
\text { (Capra hircus/Ovis aries) }\end{array}$} & Costilla & 3 & \multirow[b]{4}{*}{$21 \%$} \\
\hline & Tibia & 14 & \\
\hline & Metápodo & 8 & \\
\hline & Tibia/Metápodo & 1 & \\
\hline \multirow{2}{*}{$\begin{array}{l}\text { Suido } \\
\text { (Sus scropha/Sus domesticus) }\end{array}$} & Colmillo & 1 & \multirow[b]{2}{*}{$11 \%$} \\
\hline & Fíbula & 13 & \\
\hline \multirow[t]{5}{*}{ Mesomamífero } & Costilla & 3 & \multirow[b]{5}{*}{$19 \%$} \\
\hline & Tibia & 2 & \\
\hline & Metápodo & 13 & \\
\hline & Tibia/Metápodo & 7 & \\
\hline & Fíbula & 1 & \\
\hline Elefante (Elephas sp.) & Marfil & 8 & $7 \%$ \\
\hline Lince (Lynx sp.) & Húmero & 1 & $1 \%$ \\
\hline \multirow[t]{2}{*}{ Carnívoro } & Fíbula & 2 & \multirow[b]{2}{*}{$2 \%$} \\
\hline & Radio & 1 & \\
\hline Isurus hastalis (fósil) & Colmillo & 2 & $1 \%$ \\
\hline \multirow[t]{2}{*}{ No identificado } & Tibia/Metápodo & 6 & \multirow[b]{2}{*}{$5 \%$} \\
\hline & Falgante & 1 & \\
\hline
\end{tabular}

Fig. 2. Especies de mamíferos y aves y partes anatómicas de cada una de ellas empleadas para la manufactura de artefactos en el asentamiento de Los Castillejos. 
Nocete et al. 2012). Sí podemos señalar que al menos uno de los botones de perforación en $\mathrm{V}$ documentado en Los Castillejos fue muy probablemente realizado sobre marfil fósil ${ }^{1}$, si bien para el resto de piezas habrá que esperar hasta que puedan llevarse acabo los análisis microscópicos, espectroscópicos e isotópicos que determinen su procedencia y la especie a la que pertenecen.

A pesar de la gran variedad y cantidad de restos esqueléticos de especies salvajes (Riquelme 1996), son realmente escasos los artefactos realizados con alguna parte de su osamenta. Como en casi todos los yacimientos estudiados, es el ciervo (Cervus elaphus) el animal mejor representado con un $8 \%$, si bien este porcentaje podría ser mayor si tenemos en cuenta aquélla materia prima que se incluye en el grupo Bóvido/Ciervo (18\%), y que dado su alto grado de modificación no ha podido ser determinado con mayor exactitud. No obstante, de este grupo la mayoría de tibias y metápodos deben corresponder a ciervos, ya que son las costillas el hueso escogido de forma preferente en los bóvidos. Se han documentado, además, dos falanges y un incisivo trabajados, aunque nuevamente el asta es el elemento de su osamenta con una presencia más fuerte.

Hemos de destacar la utilización de huesos de carnívoros en hasta cuatro ocasiones para la manufactura de útiles (3\%). Se trata de un húmero de Lince (Linx pardina) y de dos fíbulas y un radio de especie indeterminada, posiblemente cánidos. El empleo de osamentas de este tipo de animales es poco frecuente, aunque no excepcional (Altamirano 2011). Además, se constata la presencia de cánidos entre los restos de fauna del yacimiento, habiendo sido en algunos casos consumidos (Riquelme 1996).

Por otro lado, la presencia de jabalí (Sus scrofa) está documentada gracias al hallazgo de un colmillo y varias fíbulas (peronés). No obstante, en ocasiones es difícil diferenciar aquéllas pertenecientes a jabalí de aquéllas otras de cerdo doméstico, ascendiendo el número total de restos de suidos a $13(11 \%)$. Según los datos faunísticos, los suidos sufren oscilaciones a lo largo de la secuencia, siendo abundantes durante el Período 2 (Neolítico Medio) y especialmente importantes en el Período VII (Cobre Tardío).

En el caso de los bóvidos de Los Castillejos se nos plantea el mismo problema que hemos visto en los suidos. Ello se debe a que en el registro arqueofaunístico se observó la presencia tanto de uro (Bos taurus) como de la variedad doméstica (Bos domesticus), sobre todo para los niveles neolíticos. Son un total de nueve objetos realizados siempre sobre costilla (6\%), aunque esta cantidad podría ser algo mayor en el caso de que alguno de las piezas incluidas en el grupo Bóvido/Ciervo sea realmente del primero.

Parece que los bóvidos tuvieron un gran peso desde el Neolítico Medio hasta el Cobre Final, siendo usados como animales de carga y transporte en actividades diversas, y explotándose sus recursos cárnicos y lácteos. Según los análisis arqueofaunísticos, la mayor parte fueron sacrificados en edades adultas (Uerpmann 1978; Ziegler 1990; Riquelme 1996).

En lo que respecta a los équidos (1\%), su osamenta no se selecciona de forma habitual para ser trabajada en los conjuntos óseos que hemos estudiado de esta cronología. No obstante, en este caso sí hemos detectado la presencia de una pieza que emplea como materia prima un metápodo lateral de caballo (Equus caballus), uso que se verá incrementado ya durante II milenio a.C., tal y como el análisis de algunos contextos ha puesto de manifiesto (Altamirano 2012).

Son sin duda las osamentas de ovicápridos (Capra hircus/Ovis aries) las que vuelven a ocupar el grueso de la materia prima utilizada para la manufactura de útiles de diversa tipología, suponiendo un $21 \%$ del total analizado. Este porcentaje es seguramente algo más elevado si tenemos en cuenta que una cantidad similar posee el grupo clasificado como Mesomamíferos, del que buena parte pertenece posiblemente a cabras u ovejas. Las partes de su esqueleto vuelven a ser las habituales predominando las tibias y los metápodos, aunque se constata también el uso de algún hueso plano como las costillas.

\section{ASPECTOS FORMALES Y TECNOLÓGICOS}

De cara a desarrollar el estudio microscópico de la superficie de los artefactos para comprender qué métodos, procedimientos y técnicas intervinieron en el proceso de manufactura (Averbouh y Provenzano 1999), el material se ha organizado siguiendo los criterios tipológicos establecidos en nuestra Tesis Doctoral (Altamirano 2013a). Éstos tienen en cuenta, en un primer nivel, la distinción entre útiles (ya sean de producción o adquisición) y objetos de adorno o simbólicos. Los útiles, por su parte, se dividen en dos grandes familias según estén elaborados sobre hueso entero (conservando al menos una de las epífisis prácticamente completa) o hendido (manufacturados sobre una porción del hueso que puede o no presentar restos de una de las epífisis, según el grado de transformación del soporte). Seguidamente, ambas familias se 
subdividen en grupos atendiendo a la morfología de su extremidad activa, creándose tipos y subtipos que obedecen a criterios relativos al tipo de hueso y sus rasgos técnicos.

Del grupo de útiles, configurado por un total de 111 artefactos, hemos de destacar que en más del $70 \%$ de los casos se trata de elementos con una extremidad activa apuntada, tendencia habitual en la mayor parte de los contextos contemporáneos analizados del $\mathrm{S}$ peninsular (Maicas 2007; Altamirano 2013a). Le siguen de lejos los útiles biselados, cuya extremidad activa presenta un bisel simple o doble, teniendo un filo recto cortante y utilizados como escoplo, cuña, hacha, etc. Aparecen también útiles relacionados con el aseo personal, como algunos peines (Salvatierra 1982; Altamirano 2014a), así como otros elementos de tipología y funcionalidad diversa.

\section{ÚTILES}

\section{LOS ÚTILES SOBRE HUESO ENTERO Apuntados}

La mayor parte de los apuntados sobre hueso entero fueron realizados empleando tibias y metápodos de cabra y oveja, lo que es frecuente desde el Neolítico y durante el III y II milenios a.C. (Salvatierra 1982; Rodanés 1990; Maicas 2007; López 2011; Altamirano 2013a). En Los Castillejos aparecen útiles sobre esta materia prima desde el Cobre Antiguo hasta el Cobre Tardío, guardando una gran homogeneidad formal y técnica.

El proceso habitual para la obtención de soportes a partir de estas tibias y metápodos fue la eliminación de una de las epífisis (en las tibias siempre la proximal), mediante fracturación por percusión directa, tal y como indican los planos de fractura que se aprecian en el arranque del boquete abierto en la diáfisis (fig. 3). La regularización de los bordes de la diáfisis y la configuración del extremo activo apuntado se llevó a cabo por abrasión (fig. 4, 1-3).

Otro de los huesos que de una forma más recurrente se empleó para la manufactura de apuntados sobre hueso entero es la fíbula o peroné de suido, y conforman uno de los tipos más numerosos y mejor definidos de Los Castillejos durante el Cobre Antiguo y Pleno. Es un tipo de artefacto que se documenta en el registro arqueológico desde al menos el Neolítico Final y se mantiene sin sufrir cambios significativos hasta el Bronce Tardío (Salvatierra 1982; Maicas 2007; López 2011; Altamirano 2011; 2013a).

Todos ellos muestran una gran uniformidad formal y técnica, conservando siempre la epífisis proximal. La contraria se eliminó fácilmente por fracturación, bien por

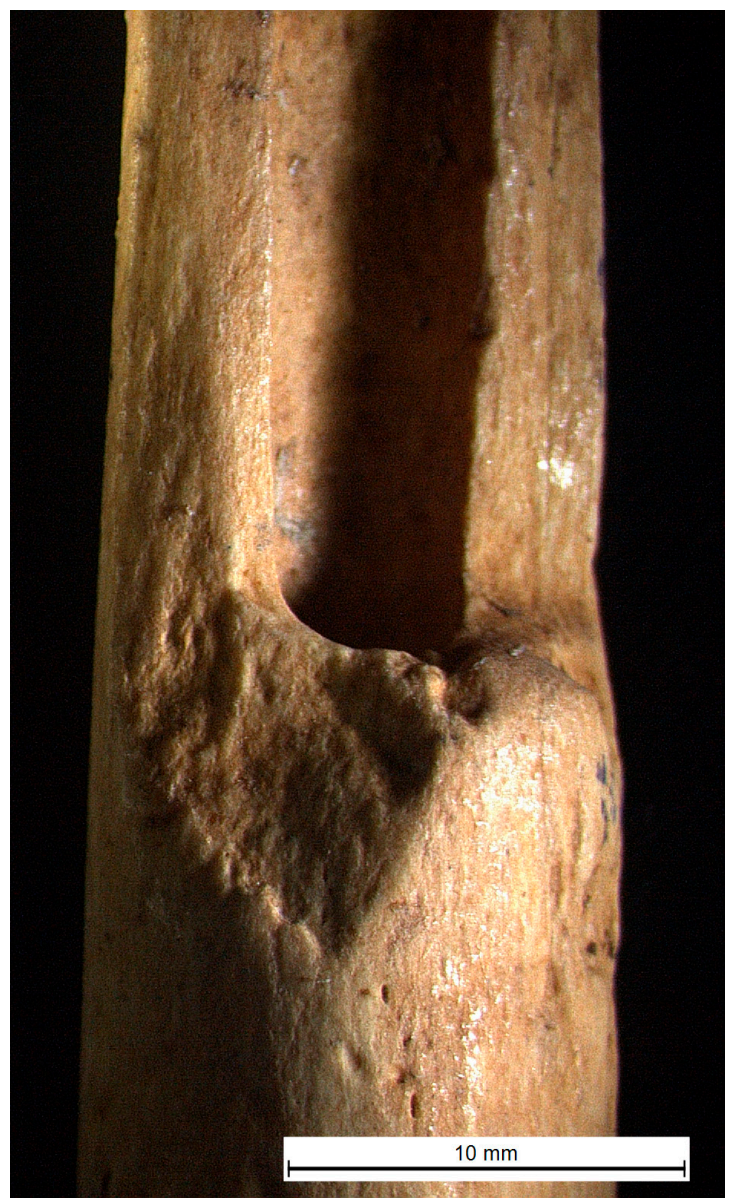

Fig. 3. Plano de fractura en el arranque de la abertura de la diáfisis, resultado de una fracturación por percusión.

percusión o bien por flexión, manufacturándose en su lugar un extremo activo apuntado (fig. 4, 4-5). Éste es realizado en la mayor parte de los casos mediante abrasión, si bien se ha documentado un caso en el que se empleó el raspado. Este ejemplar fue documentado en los niveles de la fase de transición Neolítico Final-Cobre Antiguo, por lo que podría tratarse de una manufactura de tradición neolítica.

Hemos documentado una variante de este tipo de artefacto sobre fíbula, que presenta una perforación en la parte central de la epífisis proximal, pudiendo haber sido empleado como aguja (fig. 4, 6). La perforación muestra un perímetro bastante irregular, lo que unido a la delgadez cortical del hueso en esta zona de la epífisis, podría indicar que el agujero se realizó mediante fracturación 


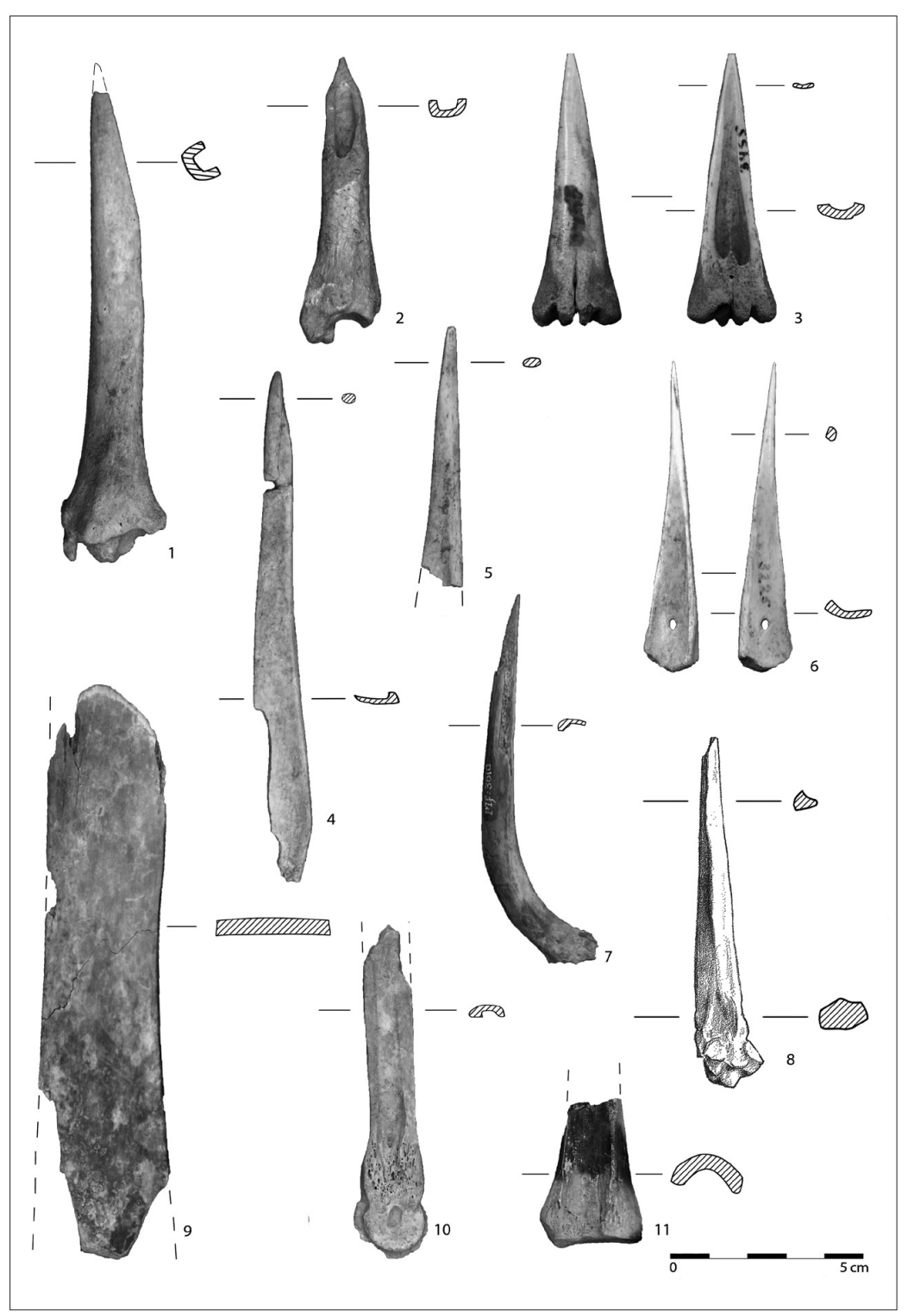

Fig. 4. Artefactos apuntados sobre hueso entero: sobre tibia (1-2) y metápodo (3) de ovicáprido, sobre fíbula de suido (46), sobre costilla de mesomamífero (7) y sobre metápodo lateral de caballo (8). Artefacto plano sobre costilla de bóvido (9). Artefactos sobre hueso hendido: sobre metápodos bipartidos de ovicáprido (10-11).

por percusión. Se han documentado artefactos similares, aunque procedentes de contextos del Bronce Tardío, empleados con bastante seguridad en actividades textiles (López 2011).

También realizados sobre fíbula, aunque en este caso de carnívoro, se han documentado dos ejemplares con una morfología similar, alargada y delgada, siendo trabajados por abrasión para configurar el extremo activo.

Las costillas de mamíferos medianos y los metápodos laterales de équido aparecen como materia prima seleccionada, aunque con una presencia muy reducida.
Tan sólo un artefacto de cada tipo se ha documentado en Los Castillejos. El apuntado sobre costilla, hallado en los depósitos del Cobre Final, se obtuvo mediante la fracturación del soporte para retirar una de las epífisis y posteriormente se aplicó la abrasión para regularizarlo con grano de tamaño mediano (fig. 4, 7). Por su parte, el apuntado sobre metápodo lateral de caballo aprovechó su morfología aguzada natural, por lo que una mínima transformación con abrasivo fue suficiente para su manufactura. Fue documentado en los niveles del Cobre Tardío (fig. 4,8). 


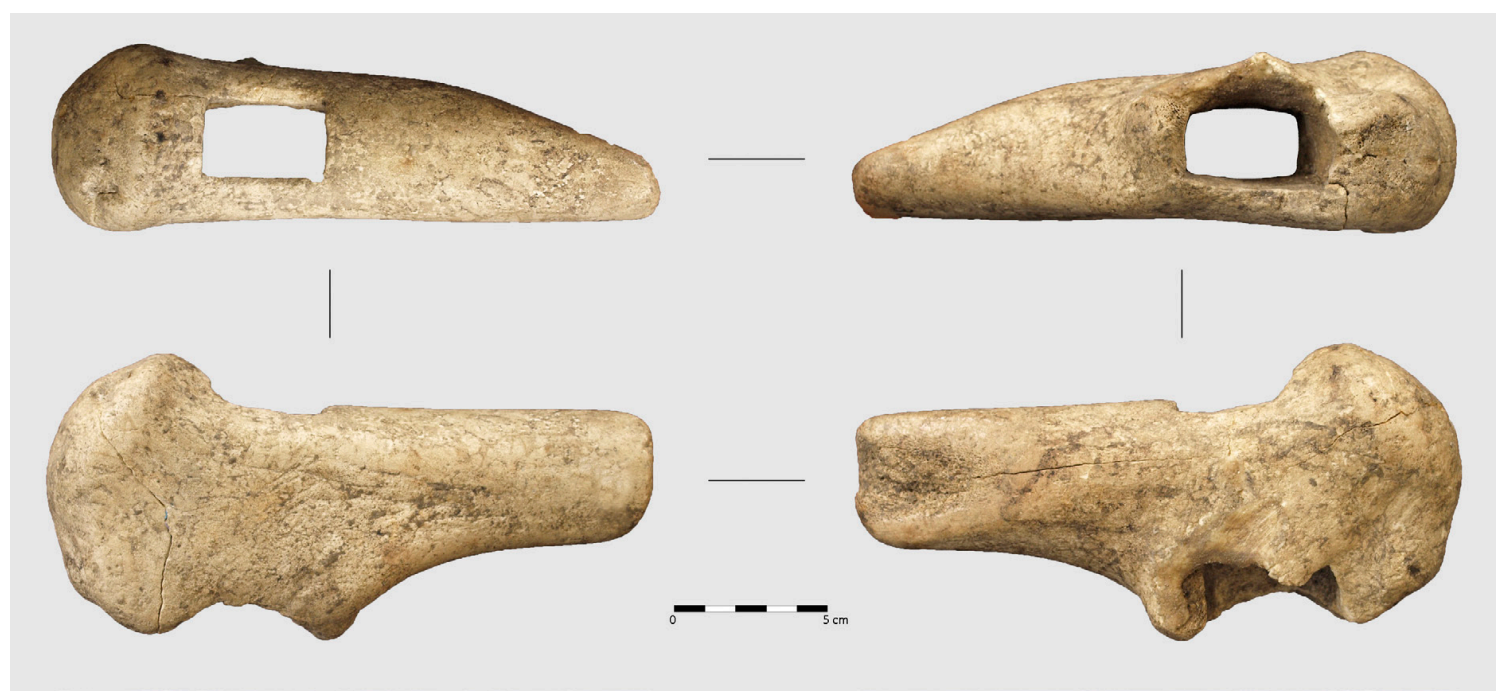

Fig. 5. Gran artefacto biselado realizado sobre asta de ciervo.

\section{Biselados}

Están representados por un único artefacto de grandes dimensiones que ha sido objeto de un estudio monográfico recientemente (Altamirano 2013b). Se trata de un útil documentado durante las excavaciones de que Miquel Tarradell (1947) llevara a cabo en el asentamiento durante los años cuarenta del s. XX (fig. 5). Pertenece a los niveles del denominado Período $\mathrm{V}$, correspondientes a un Cobre Antiguo (3300-3000 a.C.).

Es un artefacto manufacturado sobre asta de ciervo, preservando gran parte de la roseta y el medallón (aunque muy modificados) así como una porción significativa del asta principal (concretamente de la Percha A). Se procedió a retirar por un procedimiento que desconocemos la luchadera basal y de hielo. Seguidamente, se seccionó una porción del asta que incluía la zona de la roseta y el medallón, así como algo más de la mitad de la Percha A. Una vez obtenido el soporte, se trabajó seguramente por abrasión, para obtener un filo transversal al eje de la pieza. Finalmente, se practicó una perforación por vaciado, totalmente rectangular y perfectamente escuadrada en la parte media del artefacto, por la que se introduciría un mango potente de madera.

A pesar de estar incluido en el tipo definido como gran artefacto biselado, el estudio traceológico de su superficie ha revelado que el útil presenta dos partes activas bien diferenciadas. Por un lado, un gran bisel con un filo recto que crea un extremo activo adecuado para cortar o incidir en algún tipo de materia prima. Según la opinión de la traceóloga Yolaine Maigrot ${ }^{2}$, las trazas que presenta esta parte activa son indudablemente resultado de un trabajo intenso de la madera, encaminado principalmente al descortezado y desbastado. En el lado opuesto, correspondiente a la parte de la roseta del asta original, una superficie masiva y robusta de morfología convexa perfecta para ser usada como percutor. Se trata sin duda de un útil singular y excepcional, con escasos paralelos publicados en contextos similares de la península Ibérica (De Blas 2001). En cambio, sí es un útil relativamente abundante en otras zonas del continente europeo desde el Mesolítico, aunque con ligeras variaciones en cuanto al tipo de enmangue y su orientación con respecto al eje del útil (Billamboz 1977; 1979; Stordeur 1987; 1988; Sidéra 1991; Simpson 1996; Louwe 2001: 60; Provenzano 2001; Kabacinski 2009; Pratsch 2011).

\section{Planos}

Este tipo de artefacto elaborado sobre una porción de una costilla de bóvido, se ha venido definiendo en la bibliografía como perteneciente al grupo de alisadores o espátulas (López 2011). Se trata de un útil perteneciente al Cobre Pleno, realizado a partir de una costilla de bóvido, a la cual se le practicó una fractura unipolar, eliminando uno de los extremos. Los bordes presentan evidencias claras de raspado, el cual llega en algunos puntos a alcanzar el tejido esponjoso. Muestra también numerosas trazas de uso en sus superficies, especialmente en la dorsal, con un lustre y brillo intenso fruto del uso continuado 
(fig. 4, 9). Aunque está algo fragmentado, conserva uno de sus extremos redondeado y con el borde ligeramente biselado, con una serie de estigmas que algunos estudios han relacionado con ciertas actividades textiles, como el raspado de las pieles (Stone 2011).

\section{LOS ÚTILES SOBRE HUESO HENDIDO Apuntados}

Por un lado, encontramos aquéllos artefactos que emplean como soporte un hueso largo, dividido longitudinalmente y preservando parte de una de las epífisis, habitualmente la proximal. Normalmente se trata de metápodos de ovicáprido, si bien en algunos casos son de ciervo. Se documentan en Los Castillejos desde el Neolítico, observándose su continuidad hasta el Cobre Final (Salvatierra 1982; Altamirano 2013a).

En cuanto al proceso de manufactura, la bipartición longitudinal del metápodo parece que fue realizada mediante doble aserrado paralelo, a juzgar por las marcas observadas en el análisis microscópico. En la mayor parte de los útiles analizados se llevó a cabo una primera regularización del soporte para obtener la preforma del artefacto mediante raspado, consiguiéndose su aspecto final con abrasión para suavizar las aristas de la cara inferior y obtener la punta (fig. 4, 10-11). Suelen presentar secciones cóncavo-convexas en la zona meso-proximal y medial, por la presencia del canal medular marcado. En la zona distal, en cambio, la sección aparece más plana o plano-convexa,

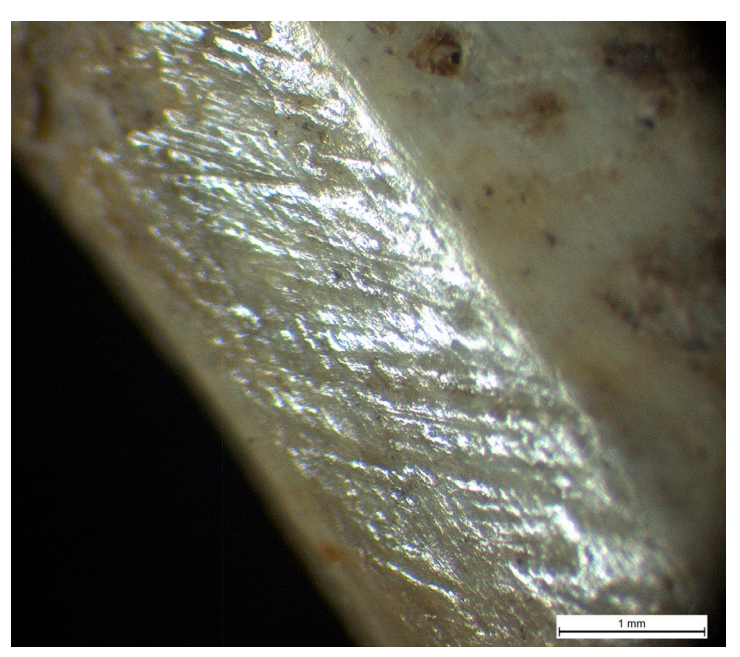

Fig. 6. Superficie desgastada y brillante originada por el uso sobre las estrías oblicuas resultado de la abrasión en la manufactura del artefacto. incluso con algún ejemplar tendente a circular. Algunos de ellos muestran superficies muy pulidas y desgastadas en la zona distal, como resultado de un uso prolongado (fig. 6).

En segundo lugar, hemos de destacar otro gran conjunto de útiles que emplearon como soporte porciones de diáfisis de huesos largos (fundamentalmente metápodos, así como algunas tibias). Se trata de artefactos sobre porciones óseas alargadas, en las que podemos diferenciar dos subtipos, atendiendo a la presencia o no del canal medular en su cara inferior, variando su sección de cóncavo-convexa a plano-convexa. Presentan en general un proceso sencillo de manufactura, bien por fracturación o bien por extracción mediante ranurado, obteniéndose soportes alargados que posteriormente eran transformados por abrasión, tal y como indican las series de estrías oblicuas y transversales que cubren la mayor parte de los bordes de la caña en la cara inferior, así como la zona distalmedial de la cara superior. Según los datos del registro arqueológico de Los Castillejos, ambos subtipos se documentan desde el Cobre Antiguo, teniendo más presencia en el Pleno (fig. 7, 1-3).

También sobre porciones alargadas de diáfisis encontramos los alfileres, unos elementos muy bien definidos y característicos del Cobre Pleno y Tardío, con una extremidad activa apuntada y una parte proximal regularizada y con formas abiertas, a modo de cabeza marcada (fig. 7, 4-6). Presentan un acabado extremadamente cuidado, con evidencias claras de uso y mantenimiento frecuente.

Encontramos también otro tipo de artefacto cuyo proceso de manufactura es quizás el más simple y en el que se aprecia un escaso interés por darle un aspecto final cuidado, invirtiéndose un mínimo tiempo y esfuerzo en su fabricación. Son los denominados como apuntados sobre esquirla, con hasta diez ejemplares documentados en Montefrío en los depósitos del III milenio a.C., aunque V. Salvatierra ya señala su presencia desde el Neolítico (1982). Los soportes se obtuvieron en todos los casos mediante la fracturación del bloque original en varios fragmentos irregulares de diverso tamaño, cuya única modificación posterior fue el acondicionamiento de un extremo aguzado mediante un tratamiento abrasivo, observándose en el resto del útil marcadas aristas y planos de fractura (fig. 7, 7).

Elaborados sobre porciones de diáfisis hemos de mencionar otro tipo de útil muy bien representado en el asentamiento, especialmente en la fase plena del Cobre. Se trata de los apuntados laminares, realizados tanto en huesos largos de grandes y medianos mamíferos como en 
Fig. 7. Artefactos apuntados: sobre porciones de diáfisis de huesos largos con restos del canal medular (1-2) y sin evidencias del mismo (3); alfileres de cabeza marcada (4-6); sobre esquirla de hueso largo (7); laminares sobre hueso largo (8-9); laminares sobre costilla (10-11).

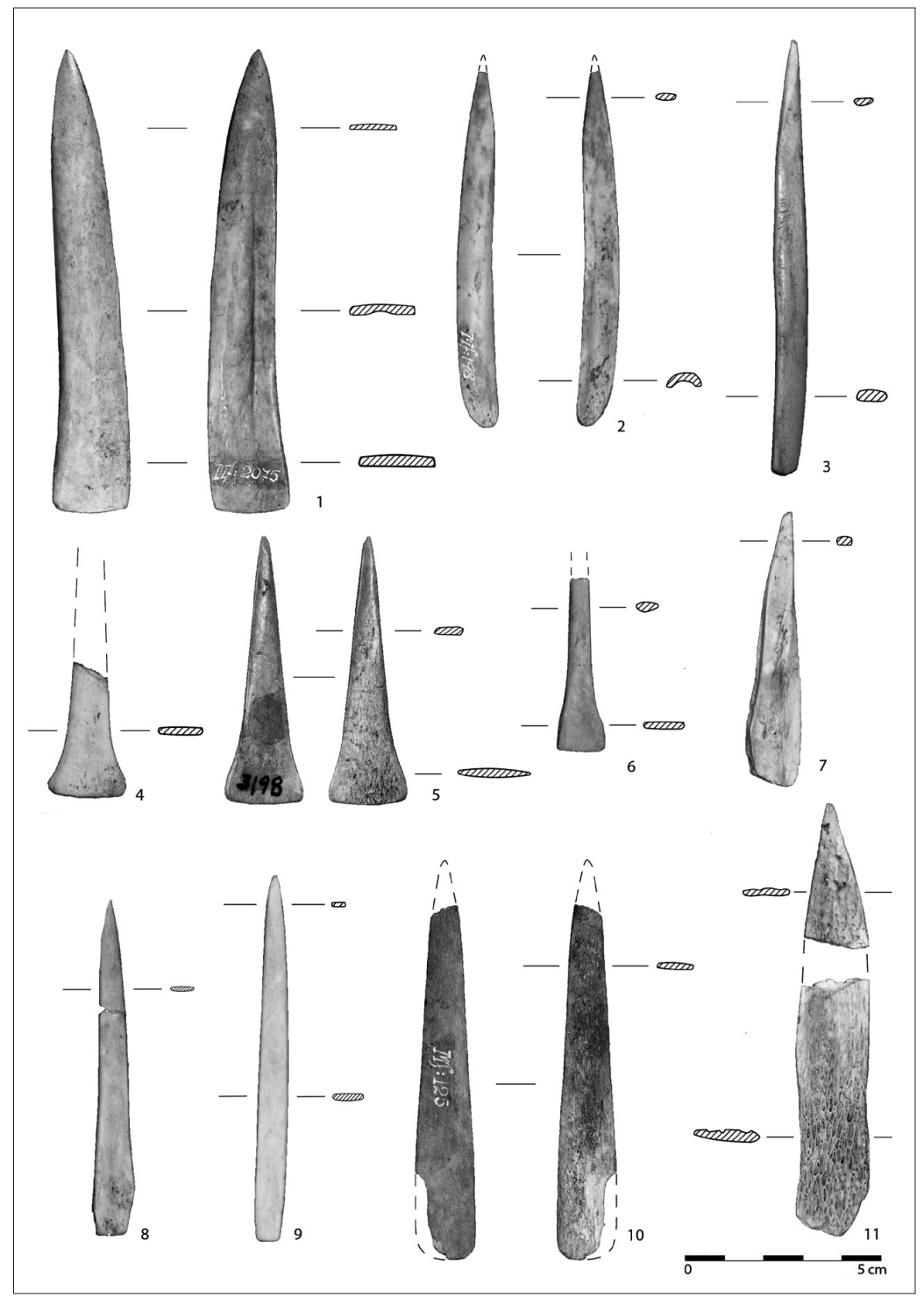

costillas de bóvido. En el caso de aquéllas piezas sobre porciones de diáfisis, el estudio técnico de los artefactos ha revelado el uso de la extracción por doble ranurado para obtener soportes alargados que posteriormente se trabajan intensamente por abrasión o raspado. Muestran un acabado cuidado, resultando útiles delgados de secciones muy planas y fuste bastante rectilíneo y que suelen presentar un talón o base recto (fig. 7, 8-9).

En el caso de los laminares sobre costilla, ésta era dividida longitudinalmente, obteniéndose soportes muy planos trabajados después con abrasión para homogeneizarlos y conseguir un extremo activo apuntado. La cara inferior está marcada por la presencia de abundante tejido esponjoso, cuya intensidad disminuye hacia la extremidad distal, a consecuencia del tratamiento por abrasión y del uso del artefacto (fig. 7, 10-11).

Otro tipo de útil llamativo dentro de los apuntados son los perforados, o agujas, del cual tan sólo encontramos un ejemplar fragmentado realizado sobre una porción de hueso. Este artefacto está posiblemente manufacturado sobre un radio de carnívoro, y fue documentado en los depósitos del Cobre Tardío. Presenta una perforación 
bipolar en su parte proximal, la cual fue efectuada con un movimiento rotatorio (fig. 8; fig. 9, 1). La parte distal está fragmentada, aunque dada su morfología pensamos que pudiera haber sido apuntada. No obstante, no podemos descartar su posible uso también como colgante.

Para finalizar con los útiles apuntados sobre hueso hendido, encontramos un tipo de artefacto realizado sobre la parte meso-distal de una luchadera o candil de ciervo divididos longitudinalmente, regularizándolos después por abrasión (fig. 9,2).

\section{Biselados}

Únicamente dos artefactos con una extremidad activa biselada forman parte de los útiles sobre hueso hendido. Por un lado, un pequeño fragmento distal de un útil que

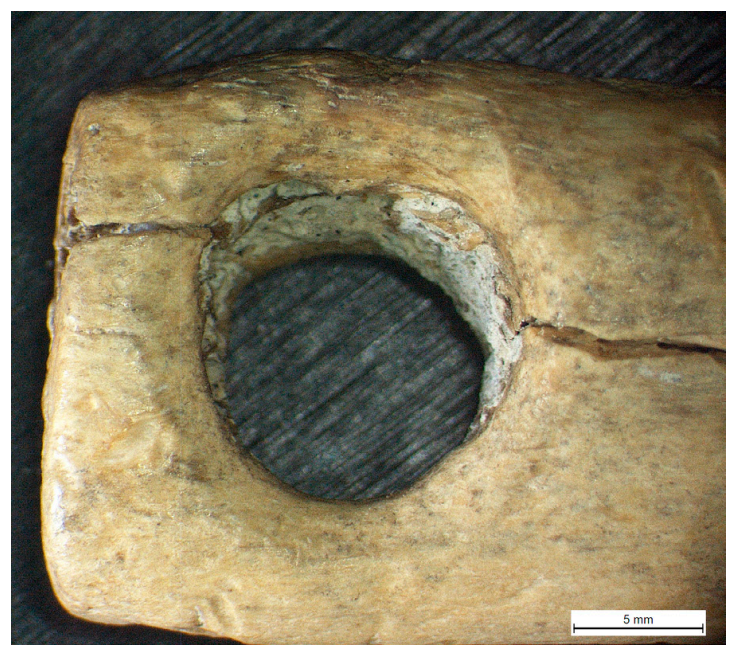

Fig. 8. Detalle de la perforación bipolar en el extremo proximal de la aguja. presenta un bisel simple y que está realizado sobre una porción de hueso de un mamífero de gran talla (fig. 9, 3). El análisis microscópico muestra el empleo de la abrasión para homogeneizar el artefacto, con una cara superior ligeramente convexa y la inferior aplanada. Procede de los niveles de transición del Neolítico Final al Cobre Antiguo.

En segundo lugar, un artefacto de doble bisel del Cobre Tardío que muestra una morfología masiva y resistente, y fue manufacturado a partir de un soporte obtenido por la bipartición longitudinal de un metápodo de un gran mamífero, dado el grosor notable de la pared cortical (fig. 9 , 4). Posteriormente fue manufacturado por abrasión, biselando ambas caras en la zona distal y obteniendo un filo recto. No obstante, éste se muestra hoy ligeramente oblicuo con respecto al eje longitudinal del artefacto, tal vez como resultado de los sucesivos reavivados para mantenerlo funcional. La parte proximal, en cambio, no se modificó sustancialmente ni se regularizó, lo que podría indicar que este útil se empleó enmangado en madera, facilitando su utilización.

\section{Dentados}

Las cinco piezas dentadas o peines procedentes de Los Castillejos (Arribas y Molina 1978) y de Cueva Alta (Tarradell 1952), muestran una gran uniformidad técnica y formal. Fueron documentados en contextos fechables en un Cobre Antiguo, y han sido objeto de un estudio monográfico recientemente (Altamirano 2014a).

Manufacturados sobre porciones de costillas de bóvido bipartidas, fueron trabajados empleando fundamentalmente la abrasión para dar forma a los soportes. Seguidamente, se configuró el apéndice de forma trapezoidal o redondeada que presentan cuatro de los peines en su extremo proximal (el quinto está fracturado) (fig. 10, 1-5).

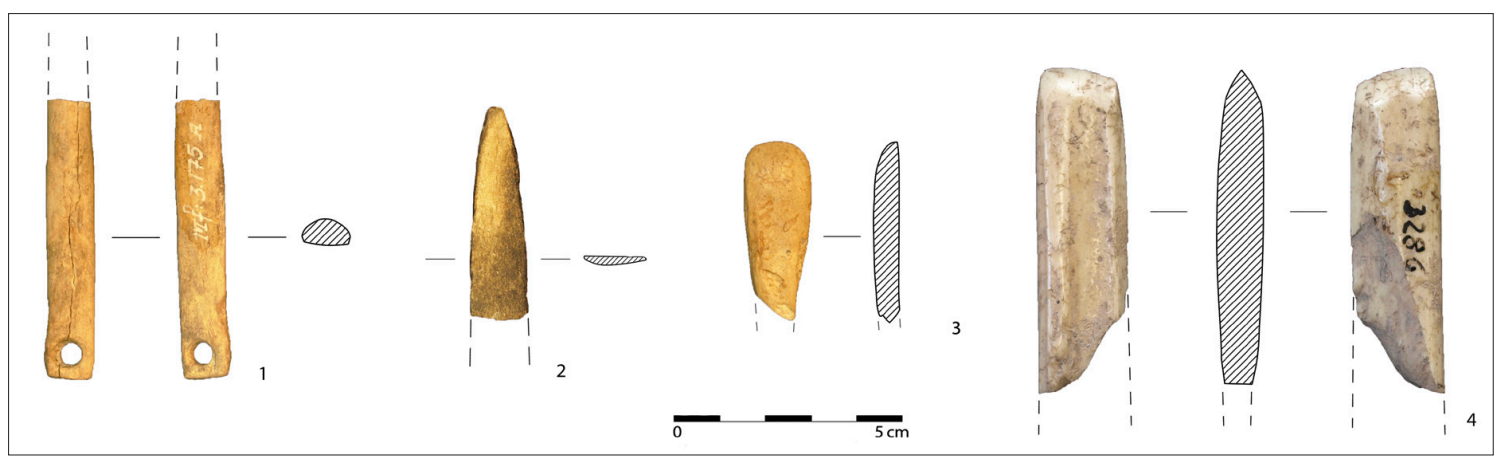

Fig. 9. Aguja de hueso (1); apuntado sobre candil de ciervo bipartido (2); biselado simple (3) y doble (4). 


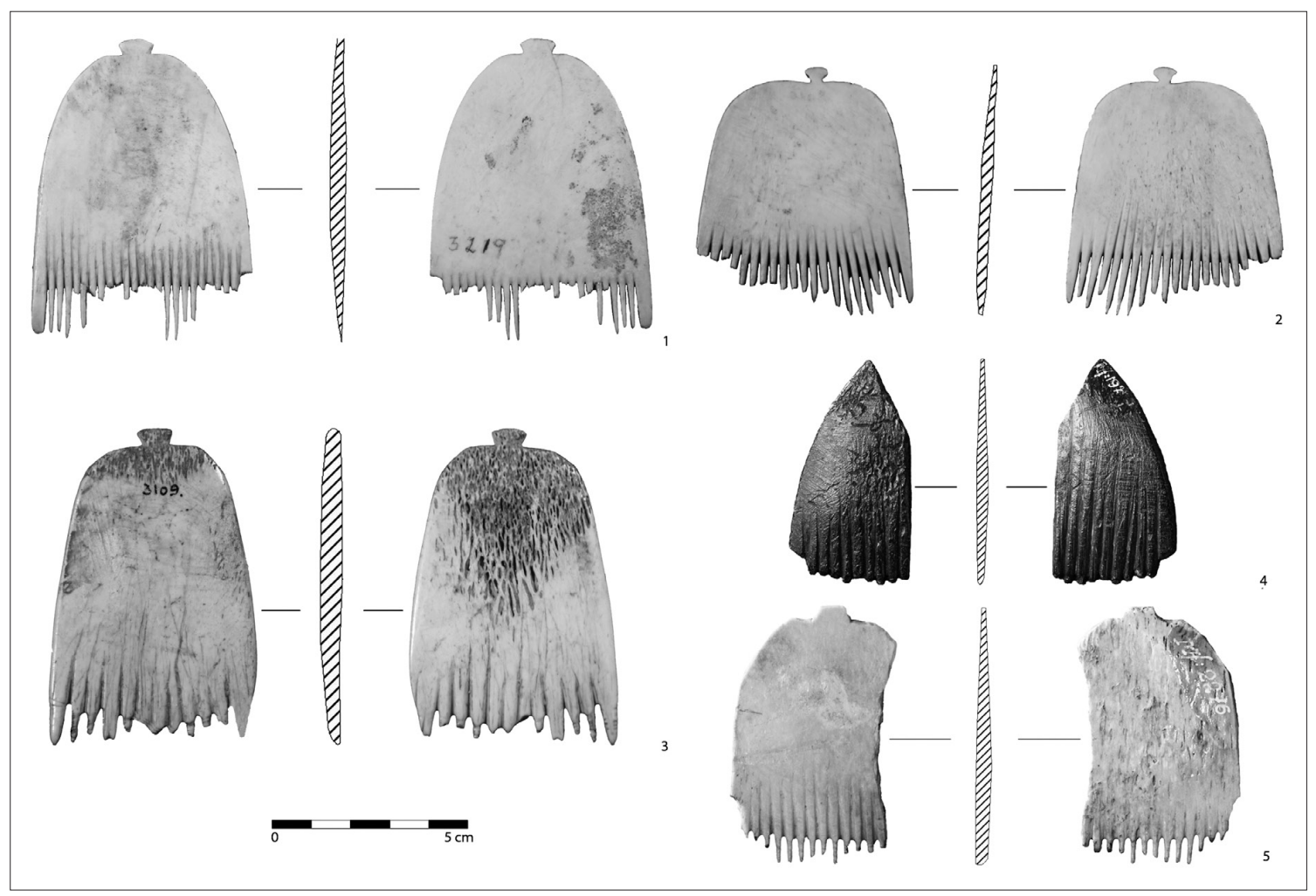

Fig. 10. Peines de hueso de Cueva Alta (1-3) y Los Castillejos de Montefrío (4-5).

En al menos un caso, este apéndice se realizó una vez regularizadas las superficies del peine mediante la abrasión, ya que se observa una continuidad entre las estrías observadas tanto en la superficie del cuerpo del peine como en la correspondiente al apéndice.

La presencia de estos apéndices o salientes en la parte proximal de estos elementos dentados se constata también para otros artefactos similares documentados en contextos de cronología similar, como uno de los dos peines de la tumba 40 del yacimiento arqueológico de Los Millares (Leisner y Leisner 1943: lám. 9, 23). Configurado el cuerpo del peine, se procedió después a definir lo que serían los dientes del mismo, siempre en el extremo opuesto al apéndice. Ésta es sin duda la parte más laboriosa y delicada de la manufactura. En este caso, la técnica escogida fue el ranurado, posiblemente con algún elemento metálico dada la sección estrecha y cerrada que muestran los surcos.

Por último, podemos avanzar que estos peines pudieron haber sido empleados en actividades de aseo y estética personal, estando relacionados con el peinado (Altamirano 2014a, b). Así parecen confirmarlo los profundos surcos

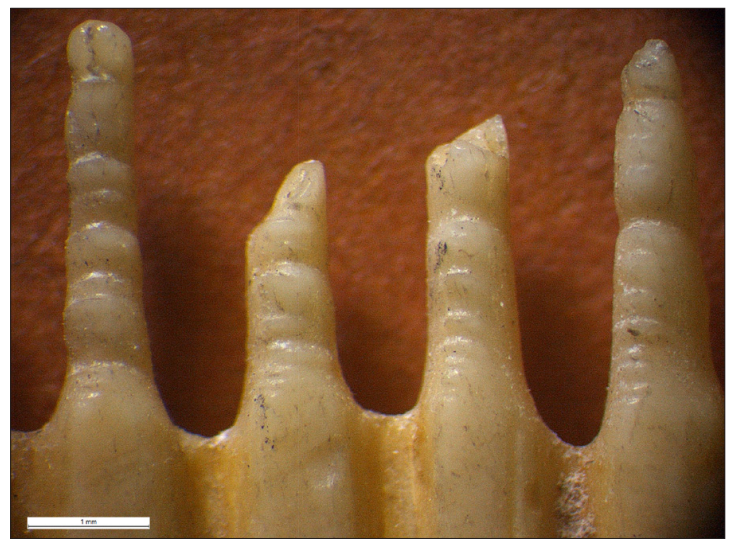

Fig. 11. Detalle de los surcos paralelos en los dientes de los peines como consecuencia de un uso prolongado, posiblemente en cabello.

paralelos y transversales que se observan en la parte proximal de cada una de las púas de los peines (fig. 11). La combinación de la grasa y las pequeñas partículas de suciedad presentes en el pelo, junto con un peinado en 


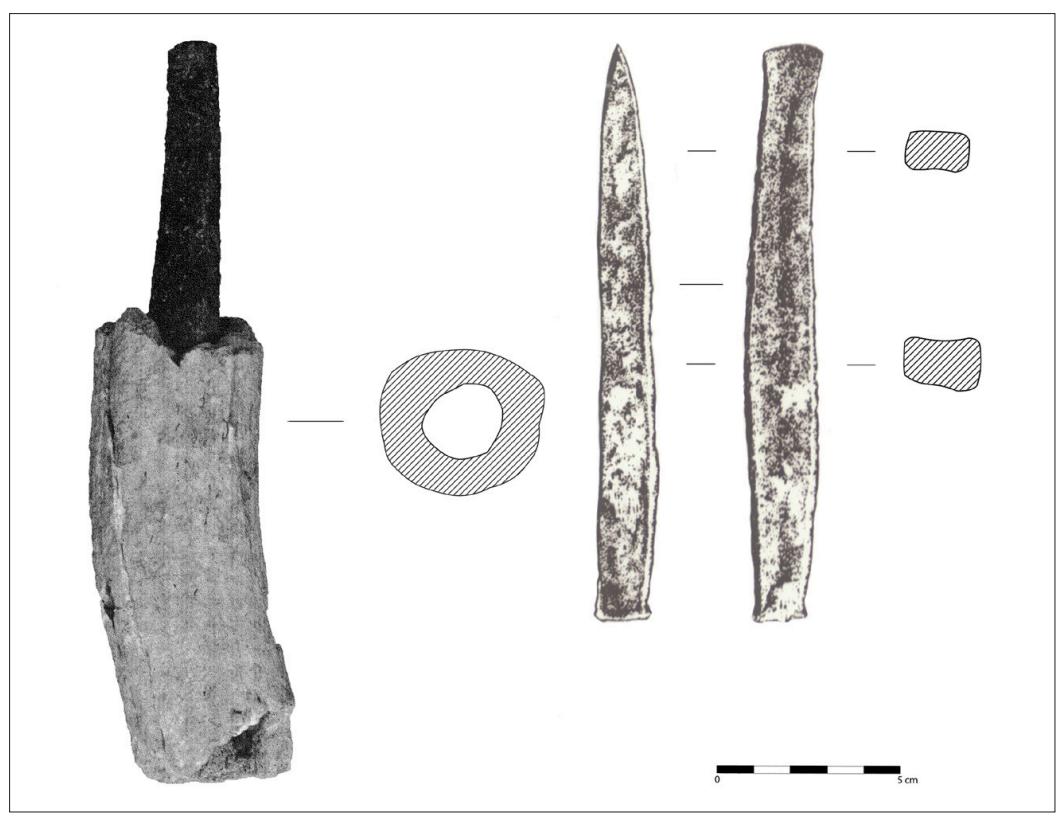

Fig. 12. Artefacto ahuecado. Mango realizado en asta de ciervo que conserva inserto un pequeño escoplo de cobre.

seco destinado básicamente a limpiar y desenredar el cabello, hacen que se produzcan este tipo de surcos en los dientes debido a la fricción continuada entre éste y los dientes del peine durante largos períodos de tiempo.

Estas evidencias vienen apoyadas por numerosos paralelos etnográficos, los cuales muestran marcas idénticas a las observadas en los peines de Montefrío. Se trata en su mayoría de peines de zonas centroeuropeas de época Moderna y Contemporánea, los cuales han sido usados diariamente durante varias generaciones por todos los miembros de una misma unidad familiar (Choyke 2006; 2009; Choyke y Kováts 2010).

\section{Ahuecados}

Finalmente, un segmento obtenido a partir del aserrado bipolar de una luchadera de asta de ciervo, la cual fue ahuecada desde uno de sus extremos hasta algo más de su mitad (fig. 12). Sabemos con seguridad que se trata de un mango, ya que fue documentado un escoplo de cobre inserto en el hueco, en los niveles del Cobre Tardío. Es interesante el uso del asta de ciervo como mango para diferentes objetos, ya que se trata de un material muy elástico que absorbe muy bien las vibraciones producidas por la percusión a la que se sometió este escoplo de metal. Objetos similares también realizados en asta empleando segmentos de luchaderas y candiles, se han documentado en otros yacimientos de la Edad del Cobre como Almizaraque (Maicas 2007: 166).

\section{OBJETOS SIMBÓLICOS/ADORNOS}

\section{CUENTAS}

Las cuentas de collar están escasamente representadas en el conjunto de industria ósea de Los Castillejos. Tan sólo se ha documentado una cuenta de morfología tubular, perteneciente al Cobre Pleno. Se trata de un fragmento de cuenta con gran alteración térmica, la cual parece estar manufacturada sobre un segmento de un hueso largo de un animal de talla mediana. La alteración de este fragmento ha dificultado notablemente su estudio traceológico, aunque se han observado estrías finas de abrasión en la zona próxima al borde (fig. 13,1).

\section{COLGANTES}

El empleo de colmillos de suido para elaborar elementos de adorno se constata ampliamente durante la Prehistoria Reciente peninsular (Fonseca 1985; Altamirano 2011; López 2011), aunque en algunos casos también parecen haber sido usados como raspadores (Altamirano 2013). El único colmillo de suido trabajado que se ha documentado fue hallado en los estratos del Cobre Antiguo.

Se manufacturó cortando longitudinalmente el colmillo y obteniendo soportes más pequeños, de los cuales nos ha llegado éste. Su superficie muestra una regularización mediante abrasión, tal y como indican las estrías finas que cubren parte de la cara inferior y los bordes (fig. $13,2)$. No se observa ningún sistema claro que hubiera 


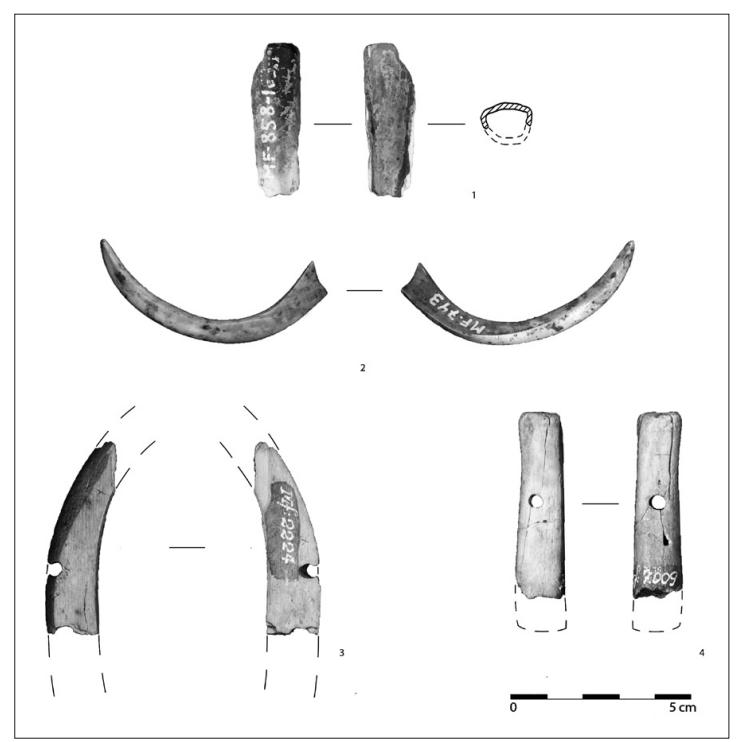

Fig. 13. Adornos: cuenta tubular de hueso (1); colgante sobre colmillo de suido (2); colgante sobre porción de marfil de elefante (3); colgante sobre tercer metacarpo de cerdo subadulto (4).

permitido suspender el objeto y emplearlo como colgante, aunque hemos de tener en cuenta que la pieza está fragmentada.

Resalta también un colgante de marfil datado en un Cobre Pleno y realizado sobre colmillo de elefante tal y como la observación de las líneas de Schreger indica. Fue manufacturado a través del corte transversal de una rodaja de marfil, la cual fue posteriormente procesada (fig. 13, 3). Presenta una sección ligeramente trapezoidal de escaso grosor, así como un perfil curvo natural. En el borde externo de su parte media se realizó una perforación unipolar desde la cara inferior, la cual está hoy fragmentada.

Vicente Salvatierra planteó la posibilidad de que se trate de una reutilización de un objeto de mayores dimensiones (1982), lo que no es de extrañar dado que se trata de una materia prima que podemos considerar exótica y de prestigio.

Por último, un posible colgante manufacturado a partir del tercer metacarpo de un cerdo subadulto, el cual fue únicamente transformado al realizar una perforación circular en una de sus caras. Fue documentado en los depósitos del Cobre Tardío (fig. 13, 4).

\section{BOTONES}

Según los datos estratigráficos, los botones de perforación en V no aparecen en Montefrío con anterioridad a un Cobre Pleno avanzado. El conjunto de botones procedente

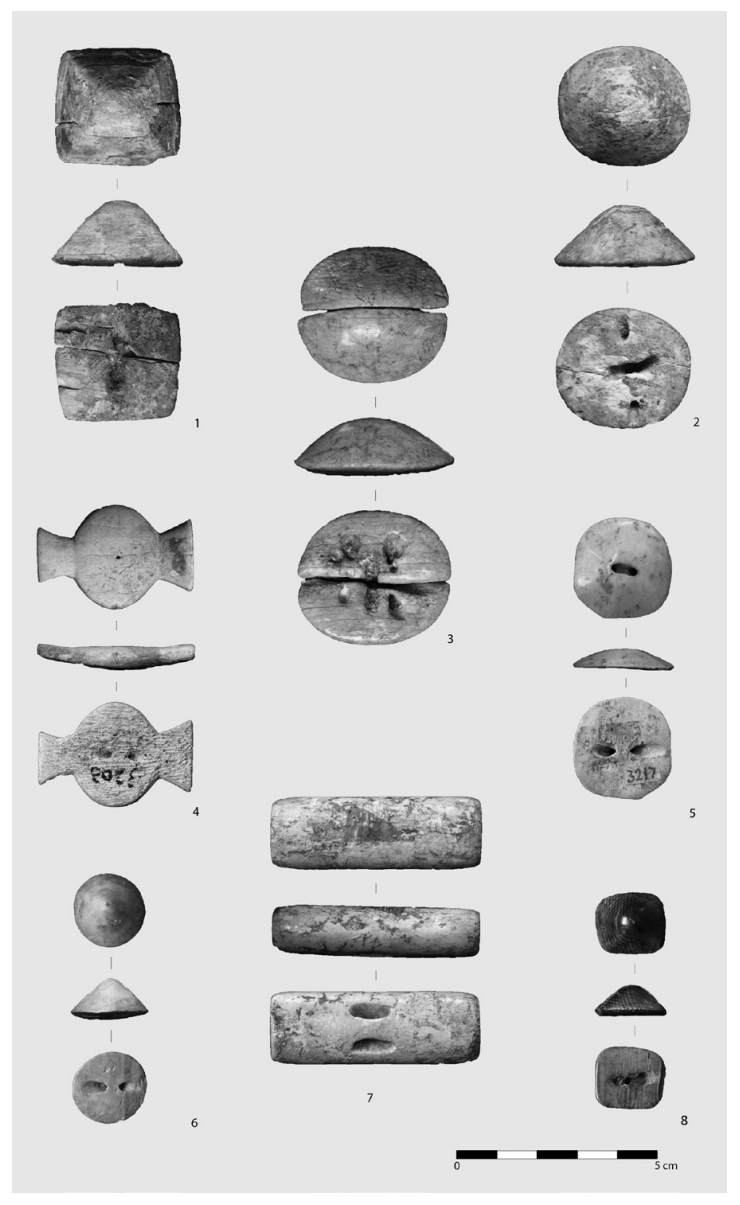

Fig. 14. Botones de marfil y asta de ciervo: cónicos $(2,6)$; hemisféricos $(3,5)$; piramidal de base rectangular (8); piramidal de base cuadrada (1); de tortuga (4); barrita semicilíndrica y sección pseudorectangular (7).

de este poblado es muy llamativo, dada la variedad tipológica y la calidad de las piezas, realizadas preferentemente sobre marfil de elefante. Uno de estos artefactos fue manufacturado sobre marfil fósil (Elephas antiquus).

Uno de los aspectos más llamativos de estos artefactos es el elevado desgaste y pulido que presentan sus superficies como consecuencia de un uso continuado durante mucho tiempo. Esto viene además avalado por la presencia de roturas y reparaciones de las perforaciones, una muestra evidente de la intencionalidad de mantenerlos en uso.

De los niveles del Cobre Pleno Avanzado, proceden un total de seis botones. En cuanto a la variedad formal, encontramos dos botones cónicos de marfil (fig. 14, 2,6), dos hemisféricos, diferenciando entre uno de base elíptica y otro de formar más lenticular (fig. 14,3,5), un 


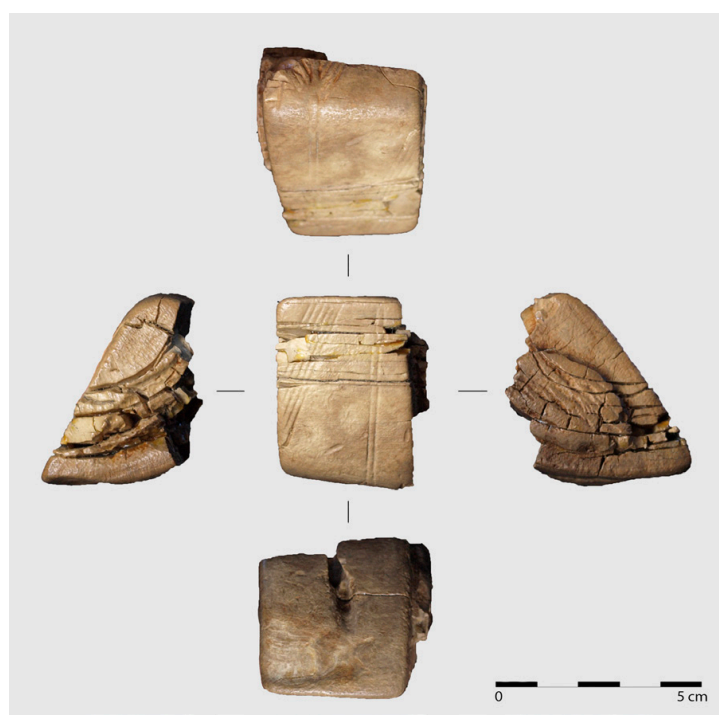

Fig. 15. Botón prismático de base rectangular con decoración lineal incisa.

pequeño botón piramidal de base rectangular (fig. 14, 8), y finalmente el único botón sobre asta de ciervo. Éste muestra dos apéndices trapezoidales en sendos extremos que delimitan una parte central más o menos circular, forma "de tortuga" (fig. 14, 4). En relación a sendos botones hemisféricos, parece probable que su morfología original correspondiera al tipo cónico, si bien el acusado desgaste superficial a lo largo del tiempo ha modificado su apariencia de forma notable (Altamirano 2014b).

A partir del Cobre Tardío, y durante el Cobre Final, se asiste a un incremento del tamaño de los botones documentados en Los Castillejos, que ya ponía de manifiesto V. Salvatierra en su tesis doctoral (1982). Destaca un botón piramidal de base más cuadrangular de mayores dimensiones que los botones piramidales de la fase anterior (fig. 14, 1), y, otro de morfología semicilíndrica sobre una barrita de marfil de sección pseudorectangular, caras convexas y laterales rectos (fig. 14, 7). Finalmente, resalta un gran botón prismático de base rectangular con decoración lineal incisa, fragmentado por su mitad (fig. 15).

\section{IDOLIFORMES}

Los elementos considerados dentro de este grupo constituyen un claro reflejo del mundo simbólico y de creencias de estas poblaciones. Según los datos del registro arqueológico, existió una cierta variabilidad en cuanto al soporte y materia prima utilizados para manufacturar los ídolos (falanges de ciervo y caballo, huesos largos enteros o porciones de los mismos, marfil, piedra, etc.), así como diversos patrones de decoración y representación de una misma realidad (Almagro 1973; Fernández y Oliva 1980; Escoriza 1990; Pascual 1998; Ortiz y Blasco 2000; Hurtado 2008; 2010; Maicas 2010).

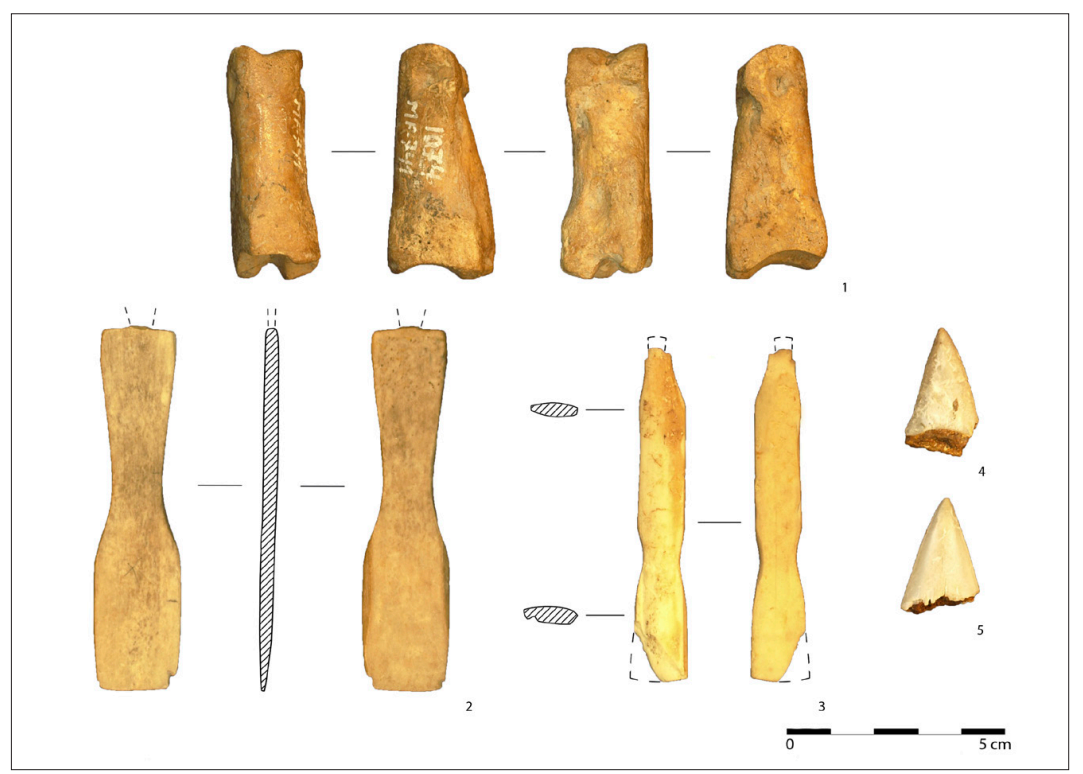

Fig. 16. Ídolo falange (1); ídolos planos con escotaduras (2-3); colmillos fósiles de tiburón (4-5). 
En Los Castillejos se han documentado por el momento dos tipos de ídolos. Por un lado, uno realizado sobre una falange de ciervo, con una ligera modificación de sus caras por abrasión (fig. 16, 1). Por otro, dos ídolos planos de cabeza marcada, o con escotaduras, similares a los que Almagro englobara en su Tipo IIf (Almagro 1973). Uno de ellos apareció en contextos del Cobre Antiguo y otro en contextos del Cobre Pleno (fig. 16, 2-3).

En sendos casos, se utilizaron soportes laminares extraídos por ranurado a partir de huesos de grandes mamíferos. Se trabajaron por abrasión, regularizando muy bien las superficies y biselando ligeramente los bordes. Presentan un estrechamiento en su parte central, delimitando dos partes en los objetos. La parte inferior, más ancha, da paso a una más estrecha, de la cual sale una especie de apéndice, que puede interpretarse como una cabeza muy esquematizada.

\section{OTROS}

Terminamos con la industria ósea de Montefrío destacando la presencia de dos colmillos fósiles de tiburón (Isurus sp.), aparecidos en contextos arqueológicos del Cobre (fig. 16, 4-5).

Fueron recogidos en las proximidades del asentamiento, donde se documentan fósiles en las formaciones terciarias del terreno circundante. No se observan modificaciones intencionales que indiquen un uso como elementos de adorno, ya que además la raíz de ambos ha desaparecido. Pudieron simplemente haber sido recolectados como objetos curiosos o cuyo significado desconocemos en el presente.

\section{DISCUSIÓN}

La gran cantidad de útiles y elementos de adorno realizados en materias óseas animales que se documenta en los yacimientos prehistóricos es una prueba indiscutible del gran papel que estos materiales jugaron en el pasado. Empleados para la fabricación de punzones, espátulas, escoplos, agujas, alfileres, hachas, peines, botones, brazaletes o colgantes, ocuparon indudablemente un lugar esencial en las actividades cotidianas, siendo también reflejo de la esfera ideológica de estas poblaciones. Tuvieron, consecuentemente, un peso fundamental en el desarrollo de las fuerzas productivas relacionadas con el proceso histórico que tuvo lugar en las diferentes zonas que configuran nuestro marco espacial.
Continuando con la línea ya planteada por otros investigadores (Choyke 2006; 2009), que incide en la importancia vital que este tipo de materias primas tuvieron en el pasado, hemos de tener en cuenta un hecho básico. Éste está en relación con que se empleara un material concreto u otro, lo que obedecía, al menos en algunos casos, a profundas y arraigadas tradiciones y creencias que nos son imposibles de conocer hoy día.

En general, podemos señalar que de las materias primas documentadas en Los Castillejos, el hueso ocupa un lugar primario, al igual que hemos observado en otros conjuntos tanto del III como del II milenio a.C., con entre un $80 \%$ y un $90 \%$ de los artefactos elaborados en este material (Altamirano 2013a). No obstante, se constata claramente cómo se seleccionan materias primas muy concretas, en ocasiones exóticas como el marfil, para manufacturar objetos con unas características técnicas y formales concretas y un significado de marcado carácter simbólico.

A partir del Cobre Antiguo (3300-3000 cal a.C. ), se incrementa la utilización de osamentas de animales domésticos, especialmente de ovicápridos, así como de suidos y bóvidos (fig. 17). De éstos se seleccionaron principalmente los huesos largos, como tibias y metápodos, aunque también las fíbulas de suido son importantes para la fabricación de artefactos. De entre los animales salvajes, se aprecia un predominio claro del ciervo (Cervus elaphus) en todos los conjuntos seleccionados especialmente los metápodos y, en menor medida, el asta. En este momento se introduce también el marfil como materia prima en el $\mathrm{S}$ peninsular, aunque parece estar más restringido al $\mathrm{Su}-$ reste y la zona de la desembocadura del Guadalquivir (Nocete et al. 2012; Schuhmacher 2012).

Estas tendencias del aprovechamiento de las materias primas óseas se acentuarán a partir del Cobre Pleno y Final y continuarán durante el II milenio a.C., con ligeros cambios. Se observa una imposición clara y progresiva de la explotación de tibias, sobre todo, y metápodos de ovicápridos, así como de las fíbulas de suido (fig. 17).

$\mathrm{Al}$ igual que sucede con otros elementos de la cultura material, los cambios en la elección de la materia prima así como las transformaciones técnicas y formales en la industria ósea se produjeron de manera gradual. De esta forma, según la información que aporta Vicente Salvatierra, vemos cómo a partir del Neolítico Tardío y Final se empieza a producir una transformación del trabajo del hueso. Los datos de los estratos datados en este momento de Montefrío, indican una mayor variedad en la materia 


\begin{tabular}{|c|c|c|c|c|c|}
\hline TIPO & \begin{tabular}{|c} 
NEOLíTICO FINAL \\
Período IV
\end{tabular} & $\begin{array}{c}\text { COBRE ANTIGUO } \\
\text { Período V }\end{array}$ & $\begin{array}{c}\text { COBRE PLENO } \\
\text { Período VI }\end{array}$ & $\begin{array}{c}\text { COBRE TARDío } \\
\text { Período VII }\end{array}$ & $\begin{array}{c}\text { COBRE FINAL } \\
\text { Período VIII }\end{array}$ \\
\hline Apuntado tibia/metápodo ovicáprido & & $\mathbf{x}$ & $\mathbf{x}$ & $\mathbf{x}$ & $\mathbf{x}$ \\
\hline Apuntado fíbula suido & $\mathbf{X}$ & $\mathbf{X}$ & $\mathbf{X}$ & & \\
\hline Apuntado fíbula carnívoro & & $\mathbf{X}$ & & & \\
\hline Apuntado costilla mesomamífero & & & & & $\mathbf{x}$ \\
\hline Apuntado metápodo équido & & & & $\mathbf{x}$ & \\
\hline Gran biselado & & $\mathbf{x}$ & & & \\
\hline Plano costilla bóvido & & & $\mathbf{x}$ & & \\
\hline Apuntado hendido metápodo & $\mathbf{x}$ & $\mathbf{x}$ & $\mathbf{x}$ & $\mathbf{x}$ & $\mathbf{x}$ \\
\hline Apuntado porción diáfisis & & $\mathbf{X}$ & $\mathbf{x}$ & $\mathbf{x}$ & \\
\hline Alfiler & & & $\mathbf{X}$ & $\mathbf{x}$ & \\
\hline Apuntado esquirla & $\mathbf{x}$ & $\mathbf{x}$ & $\mathbf{x}$ & $\mathbf{x}$ & $\mathbf{x}$ \\
\hline Apuntado laminar & & & $\mathbf{X}$ & $\mathbf{x}$ & \\
\hline Aguja & & & & & $\mathbf{x}$ \\
\hline Biselado simple & $\mathbf{x}$ & $\mathbf{x}$ & & & \\
\hline Biselado doble & & & & & $\mathbf{x}$ \\
\hline Dentados (peines) & & $\mathbf{x}$ & & & \\
\hline Ahuecado (mango) & & & & $\mathbf{x}$ & \\
\hline Cuenta tubular & & & $\mathbf{x}$ & & \\
\hline Colmillo suido & & $\mathbf{x}$ & & & \\
\hline Colgante marfil & & & $\mathbf{x}$ & & \\
\hline Colgante metacarpo & & & & & $\mathbf{x}$ \\
\hline Botón (cónico, hemisférico, piramidal y tortuga) & & & $\mathbf{x}$ & & \\
\hline Botón (prismático, piramidal y semicilíndrico) & & & & $\mathbf{x}$ & $\mathbf{x}$ \\
\hline Ídolo falange & & $\mathbf{x}$ & & & \\
\hline ídolo plano & & $\mathbf{x}$ & $\mathbf{x}$ & & \\
\hline
\end{tabular}

Fig. 17. Distribución cronológica de los tipos de artefactos, desde los últimos momentos del Neolítico (3300 cal a.C.) hasta el Cobre Final (2200 cal a.C.) según los datos desprendidos del estudio de Los Castillejos de Montefrío.

prima y en los tipos de huesos utilizados, así como la aparición de nuevos artefactos en el registro arqueológico (Salvatierra 1982).

Según los datos obtenidos del estudio formal y tecnológico de los artefactos óseos, así como los relativos al empleo y transformación de la materia prima dura animal, podemos diferenciar dos grandes etapas en Los Castillejos:

\section{NEOLÍTICO FINAL-COBRE ANTIGUO}

Existen, en general, continuidades y tradiciones en la manufactura que pueden relacionarse con algunos aspectos que hunden sus raíces en el Neolítico, como el empleo de útiles de piedra y determinadas técnicas en la manufactura. No obstante, se observan algunos cambios, como la mayor variedad en la materia prima y tipo de huesos explotados, tanto en el sureste como en la zona granadina occidental, a partir del Neolítico Final (Altamirano 2013a). En lo que respecta a los tipos de artefactos, desde al menos el Neolítico Medio podemos ver un dominio marcado de los útiles con una extremidad activa apuntada (Salvatierra 1982; Pascual 1993; Maicas 2007). Esta tendencia se verá continuada e incrementada a lo largo del III y II milenios a.C., ya que los útiles apuntados suponen habitualmente más del $90 \%$ de los artefactos que componen los conjuntos óseos trabajados.

En cuanto a las técnicas de trabajo utilizadas en la manufactura de los artefactos de esta primera etapa, se aprecia de forma clara que están directamente relacionadas con el uso de útiles líticos, como láminas, raspadores y algunos buriles (Sánchez 2000; Martínez et al. 2009). Así parecen indicarlo los negativos dejados por estos útiles en algunos de los artefactos analizados por nosotros, sobre todo en relación al procesado de la materia prima y la obtención de los soportes. 
Los métodos identificados de forma sistemática son la fracturación y la bipartición, resultando soportes bien distintos, según la finalidad. La percusión directa fue la técnica más habitual para fracturar de forma oblicua las diáfisis, retirando una de las epífisis. El ranurado, por su parte, fue el procedimiento empleado de una manera más frecuente para dividir longitudinalmente las diáfisis seguido en importancia del aserrado, documentado en un porcentaje mucho menor.

\section{COBRE PLENO-COBRE FINAL}

Se producen una serie de cambios más o menos marcados que quedan reflejados en la industria ósea. Los ovicápridos continúan siendo los mamíferos cuya osamenta se selecciona de una forma más recurrente para elaborar artefactos, seguidos en importancia de los bóvidos (metápodos y costillas), suidos (fíbulas) y, en menor medida, el caballo (sobre todo sus falanges). Las técnicas mantienen un uso mayoritario de los útiles de piedra para su puesta en práctica, a juzgar por las trazas observadas en los artefactos acabados que hemos podido analizar. No obstante, parece que los elementos metálicos comienzan a introducirse progresivamente en los procesos de trabajo de estas materias primas. En algunos casos en relación directa con el incremento de la producción de artefactos de marfil, documentándose las primeras evidencias más claras de áreas dedicadas a la transformación de esta materia prima, como la documentada en el barrio metalúrgico de Valencina de la Concepción (Vargas et al. 2012). La abrasión se mantiene como la técnica más utilizada para dar forma a los soportes y configurar los extremos activos de los útiles.

Aparecen nuevos tipos de artefactos, como pueden ser los alfileres tan característicos de este momento, con cabezas marcadas y de formas abiertas, los cuales hemos documentado en Los Castillejos (fig. 6, 4), así como en otros contextos de cronología similar como El Malagón. Otro elemento que aparece a partir del Cobre Pleno en el registro arqueológico es el denominado botón de perforación en V, tradicionalmente asociados al fenómeno Campaniforme. Es llamativo cómo estos objetos se fabrican habitualmente sobre materias primas de carácter más especial, como puede ser el marfil.

En comparación con la etapa anterior, podemos observar cómo los útiles sobre soporte laminar incrementan su presencia de manera notable, de una forma general. Por el contrario, los artefactos que conservan restos anatómicos muy marcados (epífisis, canal medular...), parecen reducir su número.

De forma paralela a las innovaciones, se constata la perduración de algunos elementos de la etapa anterior, como los apuntados tubulares sobre tibia de ovicáprido, útiles sobre tibia entera de estos mamíferos que conservan el distum (parte distal natural del hueso). Estos artefactos incluso se mantendrán en el registro arqueológico hasta el Bronce Antiguo en la zona levantina (López 2011), el sureste y la submeseta sur (Fonseca 1985; Altamirano 2010; 2011).

Otro aspecto que se ha puesto de manifiesto gracias al estudio que hemos realizado es el relativo al desgaste, mantenimiento, reparación y pervivencia en el tiempo de algunos artefactos a lo largo de muchos años. Esta intención de no desechar ciertos objetos se manifiesta claramente en dos tipos de objetos. Por un lado, aquéllos cuya manufactura es compleja y requiere una cierta inversión de tiempo y esfuerzo. Por otro, aquéllos elementos que habrían desarrollado una relación mucho más estrecha y personal con la persona o personas que lo portara/n o usara/n, normalmente sobre materias primas más especiales y con una manufactura compleja y cuidada.

Los mejores ejemplos de estos aspectos de carácter más antropológico los encontramos tanto en los botones de perforación en $\mathrm{V}$ como en los peines de Montefrío (Altamirano 2014b). En ambos conjuntos de artefactos vemos cómo los objetos son mantenidos durante varios años, en algún caso puede que incluso más de una generación de acuerdo con el desgaste de la superficie. Además, sobre todo los botones reflejan episodios de reparaciones de las perforaciones de su base, lo que muestra una intención clara por mantenerlos en uso e incluso pudiendo haber sido heredados, como proponen diversos investigadores (Choyke 2006; 2009; Choyke y Kováts 2010).

Finalmente, hemos de destacar también la existencia de conexiones simbólicas e ideológicas entre áreas culturales diferentes. Por ejemplo, en los asentamientos pertenecientes a la Cultura de Los Millares y el Grupo Megalítico Occidental Granadino. Aparte de otras similitudes a nivel de cultura material, el análisis formal y técnico de los elementos realizados en materias duras animales ha revelado unas conexiones claras entre ambos. Los elementos denominados y considerados como "ídolos", fundamentalmente los planos con escotaduras, se documentan en numerosos yacimientos del sureste y en Los Castillejos de Montefrío desde al menos los 
momentos finales del Neolítico. Algo parecido sucede con los ídolos falange, realizados mayoritariamente con falanges de ciervo que muestran una transformación más o menos pronunciada, aunque preferentemente suele ser mínima. Evidencias de éstos han sido documentadas en Los Castillejos y otros asentamientos del SE peninsular durante el III milenio a.C., si bien son un elemento que aparece de manera más habitual en el sureste (Maicas 2010; Altamirano 2013a).

Manuel Altamirano García Depto. Prehistoria y Arqueología Facultad de Filosofía y Letras

Universidad de Granada maltamirano@ugr.es

\section{NOTAS}

1. Comunicación personal del Dr. T. X. Schuhmacher. Deutsches Archäologisches Institut (DAI), Madrid.

2. Laboratoire TRAJECTOIRES, CNRS-Université Paris I, Nanterre.

\section{BIBLIOGRAFÍA}

AFONSO, J. A.; MOLINA, F.; CÁMARA, J. A.; MORENO, M.; RAMOS, R.; RODRÍGUEZ, M. O. (1996): Espacio y tiempo. La secuencia en Los Castillejos de Las Peñas de Los Gitanos (Montefrío, Granada), I Congrès del Neolític a la Península Ibérica. Formació e implantació de les comunitats agrícoles (Gavà-Bellaterra, 1995). Actes Vol. 1 (J. Bosch, M. Molist, orgs.), Rubricatum 1 (1), 297-304

ALMAGRO, M. J. (1973): Los ídolos del Bronce I Hispánico, Bibliotheca Praehistorica Hispana XII, Madrid.

ALTAMIRANO, M. (2010): La industria de hueso de un yacimiento arqueológico de la Edad del Bronce: La Motilla del Azuer (Daimiel, Ciudad Real), Arqueología y Territorio 6, Universidad de Granada, < http://www.ugr.es/ arqueologyterritorio/Artics7/Artic7_3.htm (Consulta 12-XI-2013).

ALTAMIRANO, M. (2011): Worked bone industry from the Bronze Age of Central Iberia. The settlement of La Motilla del Azuer, Written in Bones: between technology and social relations. Proceedings of the 7th Meeting of the ICAZ Worked Bone Research Group at Wroctaw, 7-11 September 2009 (J. Baron, B. Kufel-Diakowska eds.), Uniwersytet Wrocławski, 273-284.

ALTAMIRANO, M. (2012): Los útiles óseos del yacimiento de la Edad del Bronce del Cerro de la Encina (Granada), Arqueología y Territorio 9, Universidad de Granada, http:// www.ugr.es/ arqueologyterritorio/Artics9/Artic9_5.htm (Consulta 20-X-2013).
ALTAMIRANO, M. (2013a): Hueso, asta, marfil y concha: aspectos tecnológicos y socioculturales durante el III y II milenio A.C. en el sur de la Península Ibérica, Tesis Doctorales de la Universidad de Granada.

ALTAMIRANO, M. (2013b): Un hacha-martillo sobre asta de ciervo de inicios del III milenio A.C., procedente del poblado de Los Castillejos en Las Peñas de los Gitanos (Montefrío, Granada). Estudio tecnológico y funcional, Antiquitas 25, 29-38.

ALTAMIRANO, M. (2014a): Los peines óseos de los Castillejos en Las Peñas de los Gitanos (Montefrío, Granada), Actas del II Congreso de Prehistoria de Andalucía, 361-370.

ALTAMIRANO, M. (2014b): Uso y mantenimiento de objetos. Botones y peines de marfil, hueso y asta de ciervo de Los Castillejos de Montefrío (Granada), Antiquitas 26, 157-162.

ALTAMIRANO, M.; NÁJERA, T.; MOLINA, F. (2013): Bronze Age osseous projectile points from the archaeological site of La Motilla del Azuer, The sounds of Bones. Proceedings of the 8th Meeting of the ICAZ Worked Bone Research Group, Salzburg 2011 (F. Lang, ed.), ArchaeoPlus, Salzburg, 9-24.

ARRIBAS, A. (1976): Las bases actuales para el estudio del Eneolítico y la Edad del Bronce en el Sudeste de la Península Ibérica, CPUG 1, 139-155.

ARRIBAS, A.; MOLINA, F. (1977): El poblado de Los Castillejos en Las Peñas de los Gitanos (Montefrío, Granada). Campañas de excavaciones de 1971 y 1974, XIV Congreso Nacional de Arqueología (Vitoria, 1975), Zaragoza, 389-406.

ARRIBAS, A.; MOLINA, F. (1978): El poblado de Los Castillejos en las Peñas de los Gitanos (Montefrio, Granada). Campaña de excavaciones de 1971. El corte $n^{\circ} 1$, CPUG. Serie Monográfica 3, Granada.

ARRIBAS, A.; MOLINA, F. (1979): Nuevas aportaciones al inicio de la metalurgia en la Península Ibérica. El poblado de Los Castillejos de Montefrío (Granada), The origins of metallurgy in Atlantic Europe. Proceedings of the fifth Atlantic colloquium (Dublín 30th March to 4th April 1978) (M. Ryan, ed.), 7-34.

AVERBOUH, A.; PROVENZANO, N. (1998-1999): Propositiones pour une terminologie du travail préhistorique des métiers osseuses I: Les techniques, Préhistoire et Anthropologie Méditerranéennes 7-8, 5-25.

BANERJEE, A.; HUTH, J. (2012): Investigation of archaeological ivory, Marfil y elefantes en la Península Ibérica y el Mediterráneo occidental. Actas del coloquio internacional en Alicante el 26 y 27 de noviembre de 2008 (A. Banerjee, J. A. López, T. X. Schuhmacher, eds.), Iberia Archaeologica 16, Deutsches Archäologisches Institut, Diputación de Alicante, MARQ, Museo Arqueológico de Alicante, 15-28.

BILLAMBOZ, A. (1977): L'industrie du bois de cerf en FrancheComté au Néolithique et au début de l'Age du Bronze, $G a$ llia Préhistoire 20,91-176. 
BILLAMBOZ, A. (1979): Les vestiges en bois de cervidés dans les gisements de l'époque holocène. Essai d'identification de la ramure et de ses différentes composantes pour l'étude technologique et l'interprétation palethnographique, L'industrie de l'os et de bois de cervidé durant le Néolithique et l'Âge des métaux, Première réunion du groupe de travail n`3 sur l'industrie de l'os préhistorique (H. CampsFabrer, dir.), CNRS, 93-129.

CÁMARA, J. A.; MOLINA, F.; AFONSO, J.A. (2005): La cronología absoluta de Los Castillejos en Las Peñas de los Gitanos (Montefrío, Granada), Actas del III Congreso del Neolítico en la Península Ibérica (Santander, 5 a 8 de octubre de 2003), 841-852.

CÁMARA, J. A.; AFONSO, J. A; MOLINA, F. (2010): La ocupación de las Peñas de los Gitanos (Montefrio, Granada) desde el Neolítico al mundo romano. Asentamiento y ritual funerario, Las Peñas de los Gitanos (Montefrío, Granada), Ministerio de Cultura y Ayuntamiento de Montefrío.

CHOYKE, A. (2006): Bone tools for a lifetime: experience and belonging, Normes techniques et practiques sociales. De la simplicité des outillages pré- et protohistoriques. XXVI rencontres internationales d'archéologie et d'histoire d'Antibes (L. Astruc, F. Bon, V. Léa, P. Y. Milcent, S. Philibert, dirs.), 49-60.

CHOYKE, A. (2009): Grandmother's Awl: Individual and Collective Memory Through Material Culture, Materializing Memory: Archaeological Material Culture and the Semantics of the Past (I. Barbiera, A. M. Choyke, J. Rasson, eds.), 21-40.

CHOYKE, A. M.; KOVÁTS, I. (2010): Tracing the personal through generations: late medieval and ottoman combs, Bestial Mirrors. Using Animals to construct human Identities in medieval Europe (A. G. Pluskowski, G. K. Kunst, M. Kucera, M. Bietak, I. Hein, eds.), Vienna Institute for Archaeological Science, 115-127.

DE BLAS, M. A. (2001): Proceso técnico, genealogía y función del instrumental perforado en asta de ciervo de la mina de cobre prehistórica de El Milagro, BSEAA 67, 29-47.

DEL PINO, M. (1984): La Cueva de las Tontas en la estación arqueológica de Las Peñas de los Gitanos (Montefrío, Granada), $C P U G$ 9, 85-96.

ESCORIZA, T. (1990): Ídolos de la Edad del Cobre del yacimiento de Las Angosturas (Gor, Granada), Zephyrus XLIII, 95-100.

FERNÁNDEZ, F.; OLIVA, D. (1980): Los ídolos calcolíticos del Cerro de la Cabeza (Valencina de la Concepción, Sevilla), MM 21, 20- 44.

FONSECA, R. (1985): Utillaje y objetos de adorno óseos del Bronce de La Mancha, CPAUAM 11-12, 47- 55.

GÓMEZ-MORENO, M. (1907): Monumentos arquitectónicos de España, Madrid

GÓMEZ-MORENO, M. (1949): Monumentos arquitectónicos de la provincia de Granada, Misceláneas Historia-Arte-Arqueología, Primera Serie, La Antigüedad, 347-390.
GÓNGORA, M. (1868): Antigüedades prehistóricas de Andalucía, monumentos, inscripciones, armas, utensilios y otros importantes objetos pertenecientes a los tiempos más remotos de su población, Madrid.

HURTADO, V. (2008): Ídolos, estilos y territorios de los primeros campesinos en el sur peninsular, Acercándonos al Pasado. Prehistoria en 4 actos (C. Cacho, R. Maicas, J. A. Martos, M. I. Martínez, coords.), Ministerio de Cultura, Museos Estatales, Museo Arqueológico Nacional, CSIC.

HURTADO, V. (2010): Representaciones simbólicas, sitios, contextos e identidades territoriales en el Suroeste Peninsular, Ojos que nunca se cierran: Ídolos en las primeras sociedades campesinas, 16 de Diciembre de 2009, Madrid, Museo Arqueológico Nacional, 137-198.

KABACINSKI, J. (2009): Quarrying the antler adzes - a new Mesolithic site of the Boreal period at Krzyz Wielkopolski, western Poland, Quartär 56, 119-130.

LEISNER G.; LEISNER V. (1943): Die Megalithgräber der Iberische Halbinsel. Der Western, Deustsches Archäelogisches Institut. Abteilung, Madrid.

LÓPEZ, J. A. (2011): Asta, hueso y marfil : artefactos óseos de la Edad del Bronce en el Levante y Sureste de la Península ibérica (c. 2500 - c. 1300 cal BC), Serie Mayor 9, Museo Arqueológico de Alicante (MARQ).

LOUWE, L. P. (1971): Mesolithic Bone and Antler Implements from the North Sea and from the Netherlands, Berichten van de Rijksdienst from the North Sea and from the Netherlands, Jaargang 20-1, 27-73.

MAICAS, R. (2007): Industria ósea y funcionalidad: Neolítico y Calcolítico en la cuenca de Vera, Bibliotheca Praehistorica Hispana, CSIC.

MAICAS, R. (2010): Los ojos que todo lo ven, Ojos que nunca se cierran: Ídolos en las primeras sociedades campesinas, 16 de Diciembre de 2009, Madrid, Museo Arqueológico Nacional, 115-137.

MARTÍNEZ, G.; AFONSO, J. A.; CÁMARA, J. A.; MOLINA, F. (2009): Desarrollo histórico de la producción de hojas de sílex en Andalucía Oriental, Les grans fulles de sílex. Europa al final de la Prehistòria. Actes (J. A. Gibaya, X. Terradas, A. Palomo, X. Clop, eds.), Monografies 13, Museu d'Arqueologia de Catalunya, Barcelona, 15-24.

MERGELINA, C. (1941-1942): La estación arqueológica de Montefrío (Granada) I. Los dólmenes, BSEAA VIII, 33-106.

MERGELINA, C. (1945-1946): La estación arqueológica de Montefrío (Granada) II. La acrópolis de Guirrete (Los Castillejos), BSEAA XII, 15-26.

MORENO, M. A. (1982): Los materiales arqueológicos del poblado de Los Castillejos y Cueva Alta (Montefrío) procedente de las excavaciones de 1946 y 1947, CPUG 7, 235-266.

NOCETE, F.; VARGAS, J.M.; SCHUHMACHER, TH.X.; BANERJEE, A.; WINDORF, W. (2012): The ivory workshop of Valencina de la Concepción (Seville, Spain) and the identification of ivory from Asian elephant on the 
Iberian Peninsula in the first half of the 3rd millenium BC, JAS XXX, 1-14.

DOI: http://dx.doi.org/10.1016/j.jas.2012.10.028

ORTIZ, M.; BLASCO, F. (2000): Los ídolos-falange del Tholos de Huerta Montero (Almendralejo), El Megalitismo en Extremadura. Homenaje a Elías Diéguez Luengo, Extremadura Arqueológica VII, Mérida, 267-289.

PASCUAL, J. LL. (1993): El hueso trabajado y los adornos, El III milenio A.C. en el País Valenciano. Los poblados de Jovades (Cocentaina, Alacant) y Arenal de la Costa (Ontinyent, València) (J. Bernabeu, dir.), SAGVNTVM-PLAV 26, 83-98.

PASCUAL, J. LL. (1998): Utillaje óseo, adornos e ídolos del Neolítico valenciano, Trabajos Varios del SIP 95, Valencia.

PRATSCH, S. (2011): Mesolithic antler artefacts in the North European Plain, Written in Bones: between technology and social relations. Proceedings of the 7th Meeting of the ICAZ Worked Bone Research Group, Wrocław, 7-11 September 2009 (J. Baron, B. Kufel-Diakowska, eds.), Uniwersytet Wrocławski, Wroclaw, 79-92.

PROVENZANO, N. (2001): Les industries en os et bois de cervidés des Terramares Émiliennes, Thèse pour obtenir le grade de docteur de L' Université Aix-Marseille II.

RAMOS, U.; AFONSO, J.A.; CÁMARA, J.A.; MOLINA, F.; MORENO, M. (1997): Trabajos de acondicionamiento y estudio científico en el yacimiento de Los Castillejos en Las Peñas de los Gitanos (Montefrío, Granada), AAA 1993, III, 246-252.

RIQUELME, J. A. (1996): Contribución al estudio arqueofaunístico durante el Neolítico y la Edad del Cobre en las Cordilleras Béticas: el yacimiento arqueológico de Los Castillejos en Las Peñas de los Gitanos, Montefrío (Granada), Tesis Doctoral, Universidad de Granada.

RODANÉS, J. M. (1990): Industria ósea, El Calcolítico a debate. Reunión de Calcolítico de la Península Ibérica, Consejería de Cultura de la Junta de Andalucía, 159-161.

SALVATIERRA, V. (1982): El hueso trabajado en Granada: del Neolítico al Bronce final, Tesis Doctoral, Universidad de Granada.

SÁNCHEZ ROMERO, M. (2000): Espacios de producción y uso de los útiles de piedra tallada del Neolítico: el poblado de Los Castillejos de Las Peñas de los Gitanos (Granada, Espa$\tilde{n} a)$, BAR International Series 874.

SCHUHMACHER, T. X. (2012): El marfil en España desde el Calcolítico al Bronce Antiguo. Resultados de un proyecto de investigación interdisciplinar, Marfil y elefantes en la Península Ibérica y el Mediterráneo occidental. Actas del coloquio internacional, Alicante 26 y 27 de noviembre de 2008 (A. Banerjee, J. A. López, T. X. Schuhmacher, eds.),
Iberia Archaeologica 16, Deutsches Archäologisches Institut. Diputación de Alicante, Museo Arqueológico de Alicante, 45-68.

SIDÉRA, I. (1991): Mines de silex et bois de cerf: l'exemple de Serbonnes, le Revers de Brossard (Yonne), Revue Archéologique de l'Est et du Centre-Est 442, 63-91.

SIMPSON, D. D. A. (1996): Crown-Antler Maceheads and the Later Neolithic in Britain, Proceedings of the Prehistoric Society 62, 293-309.

STONE, E. (2011): Through the eye of the needle: investigations of ethnographic, experimental and archaeological bone tool use wear from perishable technologies, Dissertation submitted in partial fulfillment of the requirements for the Degree of Doctor of Philosophy Anthropology. University of New Mexico, Albuquerque (August, 2011).

STORDEUR, D. (1987): Manches et enmanchements préhistoriques: quelques propositions préliminaires, La main et l'outil. Manches et enmanchements préhistoriques, Travaux de la Maison de l'Orient 15, 11-34.

STORDEUR, D. (1988): Outils et armes en os de Mallaha, Mémoires et travaux du Centre de Recherche Français en Jerusalem 6 , Association Paléorient. Paris.

TARRADELL, M. (1947): Un yacimiento de la primera Edad del Bronce en Montefrío, Granada. Avance de los resultados de las últimas excavaciones efectuadas en Las Peñas de los Gitanos, Crónica del III C.A.S.E. 52, Murcia.

TARRADELL, M. (1952): La Edad del Bronce en Montefrío (Granada). Resultados de las excavaciones en yacimientos de las Peñas de los Gitanos, Ampurias XIV, 49-80.

UERPMANN, H. P. (1978): Informe sobre los restos faunísticos del corte $n^{\circ} 1$, El poblado de Los Castillejos en Las Peñas de Los Gitanos (Montefrío, Granada). Campaña de excavaciones de 1971. El corte número 1 (A. Arribas, F. Molina, eds.), CPUG. Serie Monográfica 3, 153-168.

VARGAS, J.M.; NOCETE, F.; SCHUHMACHER, T. X (2012): Contextos de producción de marfil en Valencina de la Concepción (Sevilla), Marfil y elefantes en la Península Ibérica y el Mediterráneo occidental. Actas del coloquio internacional, Alicante 26 y 27 de noviembre de 2008 (A. Banerjee, J. A. López, T. X. Schuhmacher, eds.), Iberia Archaeologica 16, Deutsches Archäologisches Institut, Diputación de Alicante, Museo Arqueológico de Alicante, 121-138.

ZIEGLER, R. (1990): Tierrestre aus der prähistorischen Siedlung Los Castillejos bei Montefrio (Prov. Granada), Studien über frühe Tierknochenfunde von der Iberischen Halbinsel 12, 1-46. 